Chapter 30

\title{
THE CAUSAL EFFECT OF EDUCATION ON EARNINGS
}

\author{
DAVID CARD* \\ Department of Economics, University of California at Berkeley
}

\section{Contents}

$\begin{array}{ll}\text { Abstract } & 1802\end{array}$

JEL codes $\quad 1802$

1 Introduction and overview 1802

2 The human capital earnings function $\quad 1803$

2.1 Functional form 1804

$\begin{array}{ll}2.2 \text { Measurement of education } & 1806\end{array}$

$\begin{array}{ll}2.3 \text { Which measure of earnings? } & 1808\end{array}$

2.4 Summary 1809

3 Causal modelling of the return to education 1810

$\begin{array}{ll}3.1 \text { Theoretical issues } & 1810\end{array}$

$\begin{array}{lr}3.2 & \text { Observed schooling and earnings outcomes } \\ 3.3 & 1813\end{array}$

$\begin{array}{lr}3.3 \text { Measurement error } & 1815\end{array}$

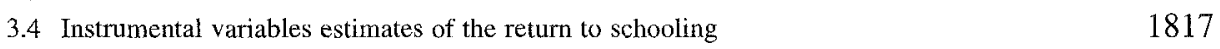

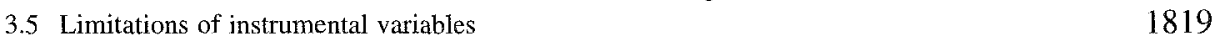

$\begin{array}{ll}3.6 & \text { Family background } \\ 3.7 & 1822\end{array}$

$\begin{array}{ll}3.7 \text { Models for siblings and twins } & 1826\end{array}$

$\begin{array}{ll}3.8 \text { Summary } & 1831\end{array}$

4 A selective review of recent empirical studies 1834

4.1 Instrumental variables based on institutional features of the school system 1834

$\begin{array}{ll}4.2 \text { Estimators using family background as a control or instrument } & 1842\end{array}$

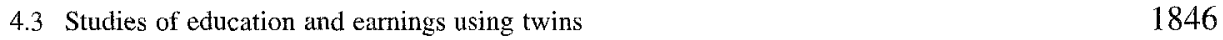

4.4 Direct evidence on the heterogeneity in returns to educution 1852

5 Conclusions 1855

Appendix A 1856

A.1 OLS estimation of a random coefficients model 1856

$\begin{array}{ll}\text { A.2 Estimation of a random coefficients model } & 1857\end{array}$

$\begin{array}{ll}\text { A.3 Measurement error in a bivariate regression model } & 1858\end{array}$

$\begin{array}{ll}\text { References } & 1859\end{array}$

* I am grateful to David Lee and Gena Estes for research assistance, to Orley Ashenfelter, Alan Krueger, and James Powell for helpful discussions, and to Michael Boozer, Ken Chay, Andrew Hildreth and Gary Solon for comments on earlier drafts that substantially improved the chapter. This research was funded in part by a grant from the NICHD. 


\begin{abstract}
This paper surveys the recent literature on the causal relationship between education and earnings. I focus on four areas of work: theoretical and econometric advances in modelling the causal effect of education in the presence of heterogeneous returns to schooling; recent studies that use institutional aspects of the education system to form instrumental variables estimates of the return to schooling; recent studies of the earnings and schooling of twins; and recent attempts to explicitly model sources of heterogeneity in the returns to education. Consistent with earlier surveys of the literature, I conclude that the average (or average marginal) return to education is not much below the estimate that emerges from a standard human capital earnings function fit by OLS. Evidence from the latest studies of identical twins suggests a small upward "ability" bias - on the order of $10 \%$. A consistent finding among studies using instrumental variables based on institutional changes in the education system is that the estimated returns to schooling are $20-40 \%$ above the corresponding OLS estimates. Part of the explanation for this finding may be that marginal returns to schooling for certain subgroups - particularly relatively disadvantaged groups with low education outcomes - are higher than the average marginal returns to education in the population as a whole. (C) 1999 Elsevier Science B.V. All rights reserved.
\end{abstract}

JEL codes: $\mathrm{I} 20 ; \mathbf{J} 30$

\title{
1. Introduction and overview
}

Education plays a central role in modern labor markets. Hundreds of studies in many different countries and time periods have confirmed that better-educated individuals earn higher wages, experience less unemployment, and work in more prestigious occupations than their less-educated counterparts. ' Despite the overwhelming evidence of a positive correlation between education and labor market status, social scientists have been cautious to draw strong inferences about the causal effect of schooling. In the absence of experimental evidence, it is very difficult to know whether the higher earnings observed for better-educated workers are caused by their higher education, or whether individuals with greater earning capacity have chosen to acquire more schooling.

Economists' interest in this issue was stimulated in the late $1950 \mathrm{~s}$ by growth accounting exercises which found that rising education levels could explain much of post-war US productivity growth, leaving little room for technological change (see, e.g., Becker, 1964; Griliches, 1970). Skeptics noted that this conclusion was only valid if the observed crosssectional earnings differences between education groups reflected true productivity differentials, rather than inherent ability differences that happened to be correlated with education (e.g., Denison, 1964). The emergence of large-scale microeconomic datasets in the 1960 s lead to an outpouring of research on education and earnings, much of it focussed on the issue of "ability bias" in the earnings differentials between more- and less-educated

\footnotetext{
'See Cohn and Addison (1997) for a selective review of recent international studies, and Psacharopoulos $(1985,1994)$ for a broad overview of the international literature on schooling and eamings.
} 
workers. In his landmark survey of the 1960s and 1970s literature, Griliches (1977) concluded that such biases were small - potentially even smaller than other biases that lead measured earnings differences to understate the causal effect of education. In his earlier review of the evidence, Becker (1964) had similarly concluded that ability biases were overstated by critics of the human capital paradigm. ${ }^{2}$ Despite the careful reasoning of these earlier surveys, however, many analysts continue to believe that the measured partial correlation between schooling and earnings significantly overstates the true causal effect of education, and that findings to the contrary are counter-intuitive.

The aim of this chapter is to survey and interpret some of the most recent evidence on the causal relationship between schooling and earnings. I focus on four key areas of research:

1. theoretical and econometric advances in modelling the causal effect of education in the presence of heterogenous returns to schooling;

2. recent studies that use institutional aspects of the education system as "exogenous" sources of variation in education outcomes;

3. recent studies of the earnings and schooling outcomes of twins;

4. recent studies that explicitly model heterogeneity in the returns to education across groups or individuals.

A unifying theme in much of this work is that the return to education is not a single parameter in the population, but rather a random variable that may vary with other characteristics of individuals, such as family background, ability, or level of schooling. In my opinion, this broader view of the effect of education helps to reconcile the various findings in the literature, and provides a useful framework for generating new hypotheses and insights about the connection between education and earnings.

The chapter begins with a brief overview of the so-called human capital earnings function, which is the primary econometric model that economists use to measure the return to education. I then present an extended discussion of a simple theoretical model of endogenous schooling that is helpful in interpreting recent empirical studies. Finally, I present a selective review and synthesis of some of the most interesting new work on education and earnings.

\section{The human capital earnings function}

Recent studies of education and wage determination are almost always embedded in the framework of Mincer's (1974) human capital earnings function (HCEF). According to this model, the log of individual earnings $(y)$ in a given time period can be decomposed into an

\footnotetext{
${ }^{2}$ Becker (1964, p. 88, footnote 30) offered the following interpretation of the prevailing opinion on the importance of ability biases: "A more cynical explanation would be that vocal observers are themselves primarily successful college graduates and, therefore, naturally biased toward the view that ability is a major cause of the high earnings received by college graduates."
} 
additive function of a linear education term and a quadratic experience term:

$\log y=a+b S+c X+d X^{2}+e$,

where $S$ represents years of completed education, $X$ represents the number of years an individual has worked since completing schooling, and $e$ is a statistical residual. In the absence of direct information on experience Mincer proposed the use of "potential experience": the number of years an individual of age $A$ could have worked, assuming he started school at age 6, finished $S$ years of schooling in exactly $S$ years, and began working immediately thereafter: $X \equiv A-S-6$. Although Mincer derived this equation from a theoretical model of schooling choice and post-schooling training decisions, the basic patterns of variation of earnings by age and education had been known at least since the early 1950 s (e.g., Miller, 1955). ${ }^{3}$ Thus the HCEF can be seen as an extraordinarily successful marriage of inductive and deductive reasoning.

\subsection{Functional form}

The simple specification of Eq. (1) immediately raises a number of questions that have been addressed directly and indirectly over the past 20 years. Many of these concern functional form. Mincer's equation can be regarded as an approximation to a general functional form,

$\log y=F(S, A)+e$.

Since both $S$ and $A$ are measured as discrete variables in most datasets, the function $F($ ) can be estimated non-parametrically by including a complete set of dummy variables for all $(S, A)$ pairs, or by using non-parametric smoothing methods (e.g., kernel density estimators) in smaller datasets. ${ }^{4}$ Alternatively, researchers have added higher-order terms in schooling and age or experience to (1) and examined the improvement in fit relative to Mincer's original specification. A comprehensive study along the latter lines by Murphy and Welch (1990) concluded that a generalization of Mincer's model

$\log y=a+b S+g(X)+e$,

where $g$ is a third or possibly fourth-order polynomial, provides a significant improvement in fit.

Some recent evidence on the shape of the $F()$ function and the performance of a specification like $\left(1^{\prime}\right)$ is provided in Fig. 1, which shows actual age-earnings profiles for

\footnotetext{
${ }^{3}$ Miller (1955, pp. 64-67) displays the age protiles of annual earnings data for men in the 1950 Census for three different education groups and remarks on both the concave nature of these profiles, and the fact that the profile for better-educated men peaks about 10 years later than the profile for less-educated men. Miller's analysis of the 1960 Census data (Miller, 1966) confirmed these same tendencies.

${ }^{4}$ In most US datasets, for example, $S$ takes on 18 or 20 discrete values and $A$ ranges from 16 to 66 , implying a maximum of about 1000 points in the range of $F()$. Zheng (1996) uses formal testing methods to compare the fit of expanded various versions of (1) to kemel density estimates using March 1990 Current Population Survey data.
} 
a. Hourly Wage Profiles for Men

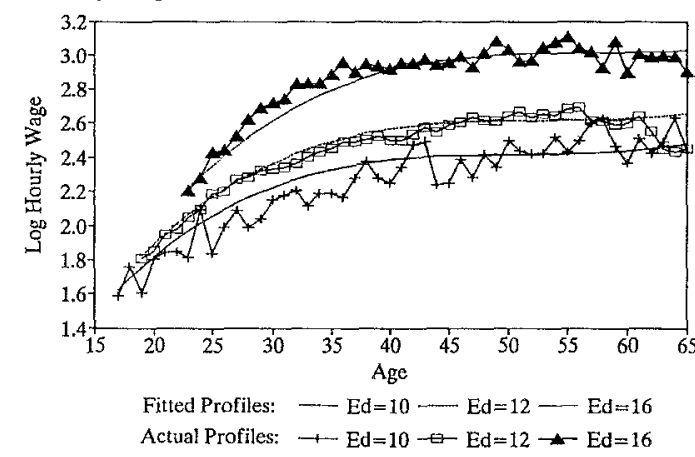

b. Hourly Wage Profiles for Women

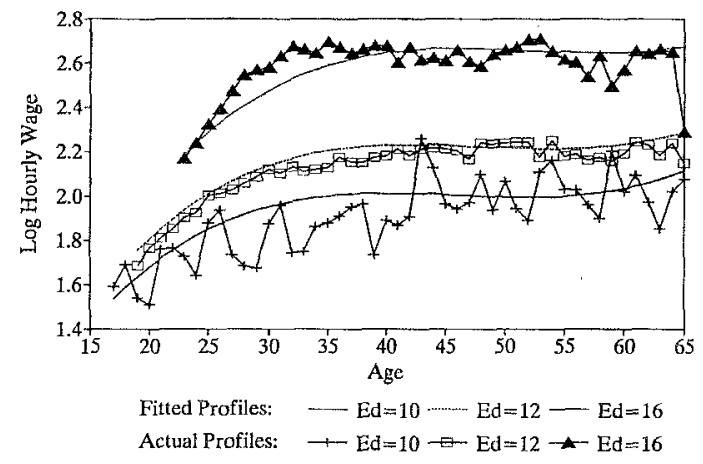

Fig. 1. Age profiles of hourly wags for men (a) and women (b).

men and women using pooled samples from the 1994, 1995, 1996 March Current Population Surveys. The data represent mean log hourly earnings by single year of age for individuals with 10,12 and 16 years of education. Plotted along with the actual means are the fitted values obtained from models like $\left(1^{\prime}\right)$ that include a cubic term in potential experience. ${ }^{5}$ Comparisons of the fitted and actual data suggest that age-earnings profiles for US men and women are fairly smooth, and are reasonably well-approximated by a simple variant of the standard human capital earnings function. Nevertheless, even a cubic version of Mincer's model has some trouble fitting the precise curvature of the age profiles for different education groups in recent US data. In particular, the fitted models tend to understate the growth rate of earnings for younger college-educated men and women relative to high-school graduates, suggesting the need for more flexible interactions

\footnotetext{
${ }^{5}$ The samples include 102,718 men and 95,360 women age 16-66 with positive potential experience and average hourly earnings between $\$ 2.00$ and $\$ 150.00$ in 1995 dollars. Fifty-three percent of the sample have 10 , 12 , or 16 years of schooling and are used in graphs. The regression models are fit by gender to all education groups and include a linear education term, a cubic in experience, and a dummy variable for individuals of black race.
} 
between education and experience. For some purposes these mis-specifications may not matter much. In other applications, however, biases in the fitted age profiles of different education groups may lead to serious misunderstandings.

\subsection{Measurement of education}

In addition to imposing separability between the effects of education and experience, the standard human capital earnings function dictates that log earnings are a linear function of years of completed education. There are two (related) hypotheses embedded in this specification: first, that the correct measure of education is the number of years of completed education; and second, that each additional year of schooling has the same proportional effect on earnings, holding constant years in the labor market. Assuming that these conditions are satisfied, the coefficient $b$ in Eq. (1) completely summarizes the effect of education in the labor market. It is now conventional to refer to $b$ as "the return to education". 6 As shown in Willis (1986, p. 532) if (1) or $\left(1^{\prime}\right)$ is correctly specified then $b$ is in fact the internal rate of return to schooling investments, assuming that education is free and that students earn nothing while in school.

The use of years of completed education as a measure of schooling has a long history in the United States. Such data were collected in the 1940-1980 Decennial Censuses and in the Current Population Surveys from the 1940s to the early 1990s. Years of schooling has substantial face validity in the US education system, but is less natural in countries with multiple education streams (e.g., Germany or France) where high school graduation may entail different years of schooling depending on whether a student plans to go to university, vocational college, or start work right away. ${ }^{7}$

Even within the US many analysts have argued that credentials (such as a high school diploma or college degree) matter more than years of schooling per se. This hypothesis has come to be known as the "sheepskin effect" - the existence of wage premiums for fulfilling the final years of elementary school, high school, or college. Hungerford and Solon (1987) and Belman and Heywood (1991) augment a standard earnings function like (1) with variables to capture non-linearities at 8,12 , or 16 years of education. These authors find some evidence of non-linearity, especially around the 16th year of schooling (corresponding to college graduation). ${ }^{8}$ Park (1994) analyzed a large sample of CPS data and concluded that most of the apparent non-linearity at 16 years of education arises from the relatively small difference in earnings between individuals with 14 and 15 years of schooling (i.e., an exceptionally low return to the 15 th year of schooling, rather than an

\footnotetext{
${ }^{6}$ In fact, the education coefficient in any statistical model of wages (or earnings) is generally referred to as the "return to education", regardless of what other control variables are included in the model. This can lead to some confusion when age rather than potential experience $(X)$ is included as a control, since the derivative of Eq. (1) with respect to schooling holding constant age is $b-c-2 \mathrm{~d} X$. Thus the "return to education" is generally lower in models that control for age rather than experience (Mincer, 1974, p. 84).

${ }^{7}$ Historically there were some inter-state differences in education systems in the US: for example, South Carolina had only three years of high school in the early 20 th Century.

${ }^{8}$ See also Goodman (1979).
} 


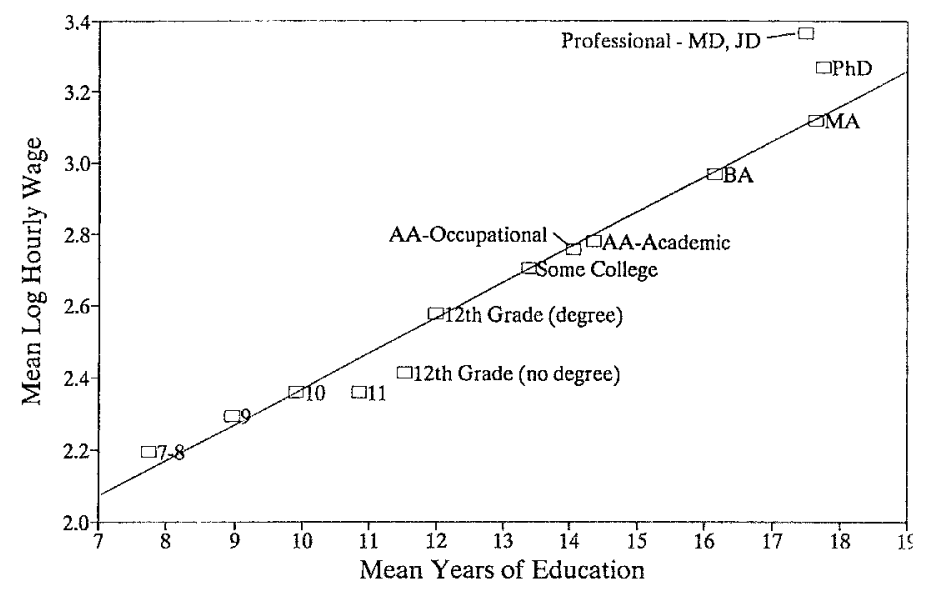

Fig. 2. Relationship between mean log hourly wages and completed education, men aged 40-45 in 1994-1996 Current Population Survey. Mean education by degree category estimated from February 1990 CPS.

exceptionally high return to the 16th year of schooling). Apart from this feature, Park shows that the linear functional form provides a surprisingly good fit to the data.

Despite economists' general satisfaction with the traditional measure of schooling, in the late 1980s the US Census Bureau decided to shift toward a degree-based system of measuring post-high-school education (see Kominski and Siegel, 1992). Thus, individuals in the 1990 Census and recent Current Population Surveys were no longer asked how many years of college they had completed: rather they were asked to report their college degrees. This change makes it more difficult to estimate the standard human capital earnings model with recent US data, or to measure changes in the structure of education-related wage differentials. Nevertheless, a concordance between the older years-of-education variable and the new degree-based variable can be constructed from a cross-tabulation of responses to the two questions included in a supplement to the February 1990 CPS. Use of this concordance provides some rather surprising support for the linearity assumption embedded in Mincer's original specification. ${ }^{9}$

Fig. 2 shows wage and schooling data for a sample of men age 40-55 in the 1994-1996 CPS. ${ }^{10}$ Mean log wages for each education group (e.g., men with a junior college or Associates degree in an academic program, denoted by "AA-Academic" in the graph) are graphed against the mean number of years of education for the group measured in the February 1990 concordance. Apart from men who report 11 years of schooling, or 12 years

\footnotetext{
"See Park (1994, 1996) for further analysis of the linearity assumption.

${ }^{10}$ I use men in this age range to abstract from the effects of experience. As shown in Fig. Ia, after age 40 the age-earnings profiles of different education groups are roughly parallel.
} 
with no high school degree, the data for individuals with between 7 and 18 years of education lie remarkably close to a line that joins the high school graduates and the college graduates (superimposed on the figure). The two highest-education groups are also off the line. My guess is that this reflects the censoring of the years-of-schooling variable, which was only reported to a maximum of 18 years. ${ }^{11}$ Based on the patterns in Fig. 2, it may be reasonable to assign an estimate of the years of completed education to each reported education class and assume a linear functional form.

\subsection{Which measure of earnings?}

The literature on the human capital earnings function has analyzed a variety of earnings measures - annual, weekly, hourly - almost always in logarithmic form. The popularity of the $\log$ transformation reflects several factors. For one, the distribution of log earnings (especially log hourly wages) is surprisingly close to a normal distribution. Other things equal, many data analysts would therefore prefer to model the log of earnings. Another practical reason for using the log transformation is the apparent success of the standard (semi-logarithmic) human capital earnings function. As demonstrated in Fig. 1a,b, the distribution of log earnings across age and education groups is closely-approximated by the sum of a linear schooling term and a polynomial in experience. Conditional on the functional form of the right-hand side of Eq. (1), Heckman and Polachek (1974) investigated alternative transformations of earnings and concluded that the log transformation is the best in the Box-Cox class. Finally, and perhaps as important as any other consideration, the log transformation is convenient for interpretation.

The choice of time frame over which to measure earnings is often dictated by necessity: some datasets report annual earnings whereas others report hourly or weekly wages. Since individuals with higher schooling tend to work more, the measured return to schooling will be higher for weekly or annual earnings than for hourly earnings. This fact is illustrated in Table 1, which reports the estimated education coefficients from models analogous to Eq. $\left(1^{\prime}\right)$ fit to earnings and hours data for men and women in the 1994-1996 March CPS. The CPS questionnaire inquires about earnings last year, total weeks worked in the previous year, and usual hours per week last year. By construction,

Annual earnings $=$ Hourly Earnings $\times$ Hours $/$ Week $\times$ Weeks.

When log annual earnings are regressed on education and other controls, the estimated education coefficient is therefore the sum of the education coefficients for parallel models fit to the log of hourly earnings, the log of hours per week, and the log of weeks per year. In the US labor market in the mid-1990s, about two-thirds of the measured return to education observed in annual earnings data is attributable to the effect of education on earnings

\footnotetext{
${ }^{11}$ Individuals with a medical or law degree, for example, have at least 20 years of schooling, and many have more.
} 
Table 1

Estimated education coefficients from standard human capital earnings function fit to hourly wages, annual earnings, and various measures of hours for men and women in March 1994-1996 Current Population Survey"

Dependent variable

\begin{tabular}{lllll}
\hline Log & Log & Log & Log & Log \\
hourly & hours & weeks & annual & annual \\
earnings & per & per year & hours & earnings
\end{tabular}

(1)

week

(3)

(4)

A. Men

Education

coefficient

R-squared

B. Women

Education

coefficient

R-squared

0.100
$(0.001)$
0.328

0.109

(0.001)

0.247
0.018

(0.001)

0.182

0.022
$(0.001)$
0.071

0.025
$(0.001)$
0.136

0.034

(0.001)

0.074
0.042

(0.001)

0.222

0.142

(0.001)

0.403

a Notes: Table reports estimated coefficient of linear education term in model that also includes cubic in potential experience and an indicator for non-white race. Samples include men and women age 16-66 who report positive wage and salary earnings in the previous year. Hourly wage is constructed by dividing wage and salary earnings by the product of weeks worked and usual hours per week. Data for individuals whose wage is under $\$ 2.00$ or over $\$ 150.00$ (in 1995 dollars) are dropped. Sample sizes are: 102,639 men and 95,309 women.

per hour, with the remainder attributable to the effects on hours per week and week per year.

\subsection{Summary}

This brief overview suggests that the human capital earnings function is alive and well. A simple regression model with a linear schooling term and a low-order polynomial in potential experience explains $20-35 \%$ of the variation in observed earnings data, with predictable and precisely-estimated coefficients in almost all applications. Close examination reveals that the model is too parsimonious to fully characterize the joint distribution of earnings, age and schooling. Nevertheless, it provides a natural starting point for building more complex models of earnings determination, and for investigating the effects of other covariates such as race, gender, and firm characteristics. Moreover, the conventional model serves as a useful benchmark for theorizing about the effects of education in the labor market. From this point of view, the approximate linearity of earnings with respect to schooling and the separability of the effects of education and experience are useful simplifications that can aid in the formulation of tractable theoretical models. 


\section{Causal modelling of the return to education}

\subsection{Theoretical issues}

Most of the conceptual issues underlying the interpretation of recent studies of the return to education can be illustrated in the framework of a simple static model that builds on Becker (1967). According to this model, each individual faces a market opportunity locus that gives the level of earnings associated with alternative schooling choices. A static model abstracts from the dynamic nature of the schooling and earnings processes and focusses instead on the relationship between completed schooling and average earnings over the lifecycle. Such a focus is justified if people finish their formal schooling before entering the labor market (other than on a casual or part-time basis) and if the effect of schooling on log earnings is separable from the effect of experience, as is assumed in the standard human capital earnings function. In fact the transition from school to work is often a bumpy one, as young adults move back and forth between full-time or part-time enrollment and part-time or full-time work. ${ }^{12}$ Nevertheless, most people have completed their formal schooling by their mid-20s. ${ }^{13}$

An analytically tractable version of Becker's model is developed in Card (1995a). Following that presentation, let $y(S)$ denote the average level of earnings (per year) an individual will receive if he or she acquires schooling level S. ${ }^{14}$ Assume that an individual chooses $S$ to maximize a utility function $U(S, y)$, where

$U(S, y)=\log y-h(s)$

and $h$ is some increasing convex function. This function generalizes the discounted present value (DPV) objective function

$\int_{S}^{\infty} y(S) \exp (r t) \mathrm{d} t=y(S) \exp (-r S) / r$

which is appropriate if individuals discount future earnings at a rate $r$, schooling is measured in years, and it is assumed that individuals earn nothing while in school and $y(S)$ per year thereafter. The DPV objective function sets $h(S)=r S$. More generally, however, $h(S)$ may be strictly convex if the marginal cost of each additional year of

\footnotetext{
12 Angrist and Newey (1991) study the earnings changes associated with education increments acquired after young men enter the labor market on a full time basis.

${ }^{13}$ By age 24, fewer than one-fifth of US adults were enrolled in school (even on a part-time basis) in the early 1990s. A simple tabulation of enrollment rates by age suggests that the transition between school and work has become sharper over the past two decades, in the US at least. For example although enrollment rates of 20 year olds are now higher than in the late 1970s (47\% enrolled in 1992 versus $37 \%$ in 1977) the enroliment rates of people in their late 20 s are lower today (e.g., $7 \%$ for 30 year olds in 1992 versus $10 \%$ in 1977). These tabulations are from the October Current Population Survey and combine men and women.

${ }^{14}$ The market opportunity locus $y(S)$ may reflect productivity effects of higher education, and/or other forces such as signalling.
} 


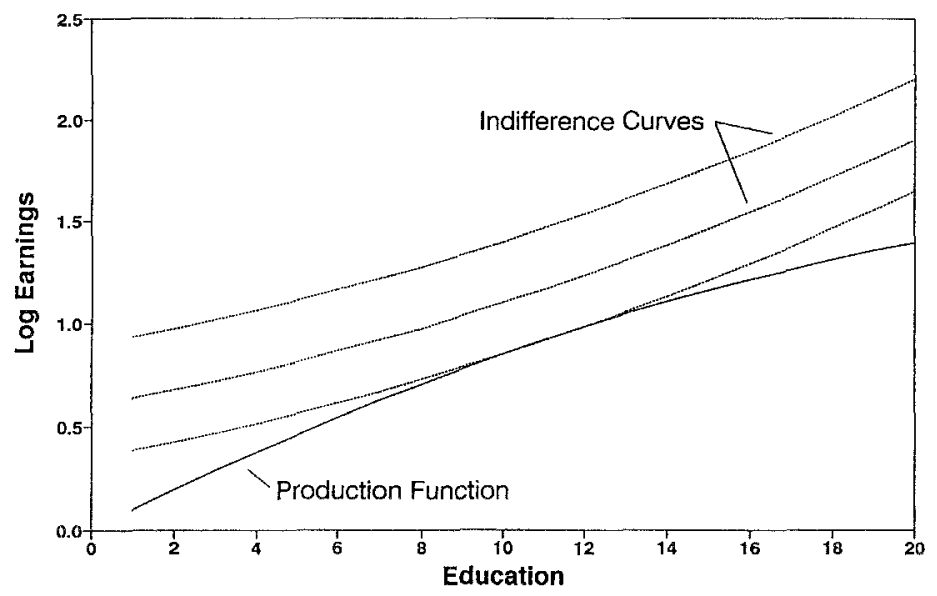

Fig. 3. Determination of optimum schooling.

schooling rises by more than the foregone earnings for that year, either because of credit market considerations (Becker, 1967) or taste factors. ${ }^{15}$

An optimal schooling choice satisfies the first-order condition

$h^{\prime}(S)=y^{\prime}(S) / y(S)$,

as illustrated in Fig. 3. An important feature of the class of preference functions defined by Eq. (2) is linearity in log earnings. This means that the indifference curves in Fig. 3 are vertically parallel, with the immediate implication that any factor that raises log earnings for all levels of schooling has no effect on the optimal schooling choice. In principle this need not be true. For example, Griliches (1977) presents a variant of DPV preferences with the feature that a uniform upward shift in log earnings for all levels of schooling leads to a lower schooling choice.

Individual heterogeneity in the optimal schooling choice illustrated in Fig. 3 arises from two sources: differences in the costs of (or tastes for) schooling, represented by heterogeneity in $h(S)$; and differences in the economic benefits of schooling, represented by heterogeneity in the marginal return to schooling $y^{\prime}(S) / y(S)$. A simple specification of these heterogeneity components is

$y^{\prime}(S) / y(S)=b_{i}-k_{1} S$,

$h^{\prime}(S)=r_{i}+k_{2} S$

\footnotetext{
${ }^{15}$ Note that the marginal rate of substitution (MRS) between income and schooling is $y(S) h^{\prime}(S)$. Under a DPV criterion MRS $=r y(S)$, since the opportunity costs of the Sth year schooling are just the foregone earnings $y(S)$. If $h^{\prime}(S)$ is increasing in $S$, the MRS rises faster than $y(S)$.
} 


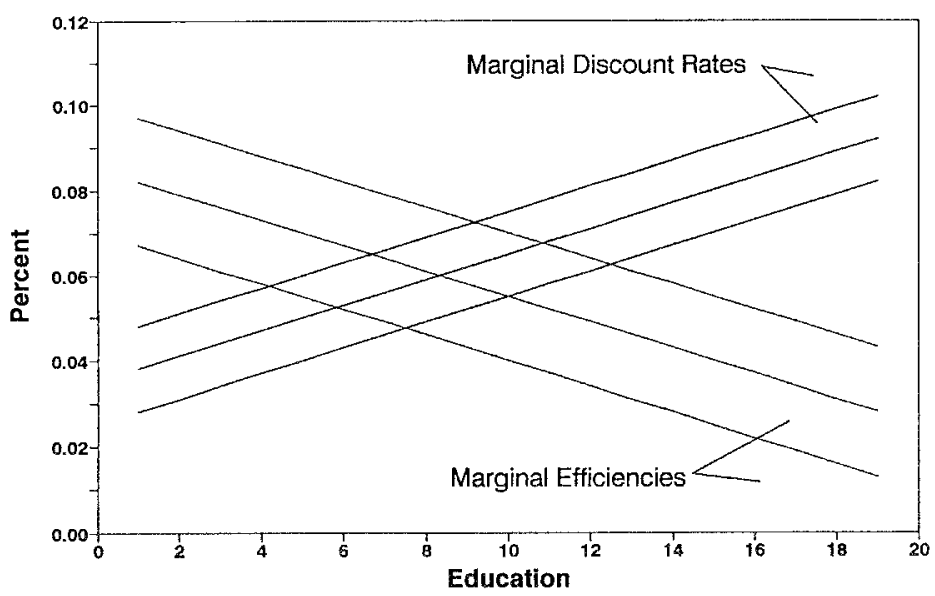

Fig. 4. Marginal benefit and marginal cost schedules for different individuals.

where $b_{i}$ and $r_{i}$ are random variables with means $\bar{b}$ and $\bar{r}$ and some joint distribution across the population $i=1,2, \ldots$, and $k_{1}$ and $k_{2}$ are non-negative constants. This specification implies that the optimal schooling choice is linear in the individual-specific heterogeneity terms,

$S_{i}^{*}=\left(b_{i}-r_{i}\right) / k$,

where $k=k_{1}+k_{2}$. Fig. 4 illustrates the determination of optimal schooling using the marginal benefit and marginal cost schedules described by Eqs. (3a) and (3b).

Since formal schooling is usually completed early in life, individuals do not necessarily know the parameters of their earnings functions when they make their schooling choices. Thus, $b_{i}$ should be interpreted as the individual's best estimate of his or her earnings gain per year of education, as of early adulthood. One might expect this estimate to vary less across individuals than their realized values of schooling. Moreover, the distribution of $b_{i}$ may change over time with shifts in labor market conditions, technology, etc. ${ }^{16}$ For simplicity, however, I will treat $b_{i}$ as known at the beginning of the lifecycle and fixed over time: this assumption probably leads to some overstatement of the role of heterogeneity of $b_{i}$ in the determination of schooling and earnings outcomes.

At the optimal level of schooling described by Eq. (4) individual $i$ 's marginal return to schooling is

$\beta_{i}=b_{i}-k_{1} S_{i} *=b_{i}\left(1-k_{1} / k\right)+r_{i} k_{1} / k$.

Even in this very simple model equilibrium entails a distribution of marginal returns

\footnotetext{
${ }^{16}$ If changes over time cause the mean return $\vec{b}$ for a cohort to rise or fall, but leave the distribution of $b_{i}$ otherwise unaffected, then the results presented below are unaffected.
} 
across the population unless one of two conditions is satisfied: (a) $r_{i}=\bar{r}$ for all $i$ and $k_{2}=$ 0 (i.e., linear indifference curves with a uniform slope $\bar{r}$ in Fig. 3); or (b) $b_{i}=\bar{b}$ for all $i$ and $k_{1}=0$ (i.e., linear opportunity locuses with a uniform slope $\bar{b}$ in Fig. 3).

In general equilibrium the distribution of marginal returns to schooling is endogenous: a greater supply of highly-educated workers will presumably lower $\bar{b}$, and might also affect other characteristics of the distribution of $b_{i} \cdot{ }^{17}$ From the point of view of a cohort of young adults deciding on their education, however, the distribution of returns to education is arguably exogenous. I therefore prefer to interpret Eq. (4) as a partial equilibrium description of the relative education choices of a cohort of young adults, given their family backgrounds and the institutional environment and economic conditions that prevailed during their late teens and early 20s. Differences across cohorts in these background factors will lead to further variation in the distribution of marginal returns to education in the population as a whole.

\subsection{Observed schooling and earnings outcomes}

To understand the implications of the preceding model for observed schooling and earnings outcomes, note that Eq. (3a) implies a model for log earnings of the form

$\log y_{i}=\alpha_{i}+b_{i} S_{i}-\frac{1}{2} k_{1} S_{i}^{2}$

where $\alpha_{i}$ is a person-specific constant of integration. This is a somewhat more general version of the semi-logarithmic functional form adopted in Mincer (1974) and hundreds of subsequent studies. In particular, individual heterogeneity potentially affects both the intercept of the earnings equation (via $\alpha_{i}$ ) and the slope of the earnings-schooling relation (via $b_{i}$ ). It is convenient to rewrite this equation as

$\log y_{i}=a_{0}+\bar{b} S_{i}-\frac{1}{2} k_{1} S_{i}^{2}+a_{i}+\left(b_{i}-\bar{b}\right) S_{i}$,

where $a_{i} \equiv \alpha_{i}-a_{0}$ has mean 0. Eqs. (4) and (5) together describe a two-equation system for schooling and earnings in terms of the underlying random variables $a_{i}, b_{i}$, and $r_{i}$.

To proceed, consider the linear projections of $a_{i}$ and $\left(b_{i}-\bar{b}\right)$ on observed schooling:

$a_{i}=\lambda_{0}\left(S_{i}-\bar{S}\right)+u_{i}$

$b_{i}-\bar{b}=\psi_{0}\left(S_{i}-\bar{S}\right)+v_{i}$

where $\bar{S}$ represents the mean of schooling and $\mathrm{E}\left[S_{i} u_{i}\right]=\mathrm{E}\left[S_{i} v_{i}\right]=0$. The parameters $\lambda_{0}$ and $\psi_{0}$ in Eqs. (6a) and (6b) are theoretical regression coefficients:

\footnotetext{
${ }^{17}$ See Freeman (1986) and Willis (1986) for some discussion of the general equilibrium implications of optimal schooling models.
} 
$\lambda_{0}=\frac{\operatorname{cov}\left(a_{i}, S_{i}\right)}{\operatorname{var}\left(S_{i}\right)}=k \frac{\sigma_{b a}-\sigma_{r a}}{\sigma_{b}^{2}+\sigma_{r}^{2}-2 \sigma_{b r}}$

and

$\psi_{0}=\frac{\operatorname{cov}\left(b_{i}, S_{i}\right)}{\operatorname{var}\left(S_{i}\right)}=k \frac{\sigma_{b}^{2}-\sigma_{b r}}{\sigma_{b}^{2}+\sigma_{r}^{2}-2 \sigma_{b r}}$,

where $\sigma_{b}^{2}, \sigma_{r}^{2}$, and $\sigma_{b r}$ denote the variances and covariance of $b_{i}$ and $r_{i}$, and $\sigma_{b a}$ and $\sigma_{r a}$ denote the covariances of $b_{i}$ and $r_{i}$ with $a_{i}$. For simplicity, assume that $b_{i}$ and $r_{i}$ have a jointly symmetric distribution. ${ }^{18}$ Then, using Eq. (A.3), and the fact that a linear projection of $S_{i}^{2}$ on $S_{i}$ has slope $2 \bar{S}$, it is readily shown that the probability limit of the ordinary least squares (OLS) regression coefficient $b_{\mathrm{ols}}$ from a regression of log earnings on schooling is

$\operatorname{plim} b_{\mathrm{ols}}=\bar{b}+\lambda_{0}-k_{\mathrm{l}} \bar{S}+\psi_{0} \bar{S}=\bar{\beta}+\lambda_{0}+\psi_{0} \bar{S}$,

where $\bar{\beta} \equiv \mathrm{E}\left[\beta_{i}\right]=\mathrm{E}\left[b_{i}-k_{1} S_{i}\right]=\bar{b}-k_{1} \bar{S}$ is the average marginal return to schooling in the population. ${ }^{19}$

Eq. (7) generalizes the conventional analysis of ability bias in the relationship between schooling and earnings (see Griliches, 1977). ${ }^{20}$ Suppose that there is no heterogeneity in the marginal benefits of schooling (i.e., $b_{i}=\bar{b}$ ) and that log earnings are linear in schooling (i.e., $k_{1}=0$ ). In this case (7) implies that

$\operatorname{plim} b_{\mathrm{ols}}-\bar{b}=\lambda_{0}$.

This is the standard expression for the asymptotic bias in the estimated return to schooling that arises by applying the "omitted variables" formula to an earnings model with a constant schooling coefficient $\bar{b}$. According to the model presented here, this bias arises through the correlation between unobserved ability $a_{i}$ and the marginal cost of schooling $r_{i}{ }^{21}$ If marginal costs are lower for children from more privileged family backgrounds, and if these children would also tend to earn more at any level of schooling, then $\sigma_{r a}<0$, implying that $\lambda_{0}>0$.

If both the intercept and slope of the earnings function vary across individuals then the situation is more complicated. Since people with a higher return to education will tend to acquire more schooling, a cross-sectional regression of earnings on schooling yields an upward-biased estimate of the average marginal return to schooling, even ignoring variation in the intercepts of the earnings function. The magnitude of this endogeneity or self-

\footnotetext{
${ }^{18}$ This assumption implies that $\mathrm{E}\left[\left(b_{i}-\bar{b}\right)^{3}\right]=\mathrm{E}\left[\left(r_{i}-\bar{r}\right)^{3}\right]=\mathrm{E}\left[\left(r_{i}-\bar{r}\right)\left(b_{i}-\bar{b}\right)^{2}\right]=\cdots=0$.

${ }^{19}$ If the random variables $r_{i}$ and $b_{i}$ are not symmetrically distributed then Eq. (7) contains an additional term equal to $\mathbf{E}\left[\left(b_{i}-\bar{b}\right)\left(S_{i}-\bar{S}\right)^{2}\right]$. See Appendix A.

${ }^{20}$ Throughout this paper I use the term "bias" to refer to the difference between the probability limit of an estimator and some target parameter: typically the average marginal return to schooling in the population under study.

${ }^{21}$ As noted earlier, the form of Eq. (2) rules out a direct connection between $a_{i}$ and optimal schooling choice.
} 
selection bias $\psi_{0} \bar{S}$ depends on the importance of variation in $b_{i}$ in determining the overall variance of schooling outcomes.

To see this, note that the variance of schooling is $\left(\sigma_{b}^{2}+\sigma_{r}^{2}-2 \sigma_{b r}\right) / k^{2}$.The fraction of the variance of schooling attributable to differences in the slope of the earnings-schooling relation (as opposed to differences in tastes or access to funds) can be defined as

$f=\frac{\sigma_{b}^{2}-\sigma_{b r}}{\sigma_{b}^{2}+\sigma_{r}^{2}-2 \sigma_{b r}}$.

Assuming that $\sigma_{b r} \leq 0$ (i.e., that the marginal benefits of schooling are no higher for people with higher marginal costs of schooling), this "fraction" is bounded between 0 and 1 . The auxiliary regression coefficient defined in Eq. (6b) is $\psi_{0}=k f \geq 0$. Thus, the endogeneity bias component in $b_{\text {ols }}$ is

$\psi_{0} \bar{S}=k f \bar{S} \geq 0$.

Even ignoring the traditional ability bias term $\lambda_{0}, b_{\text {ois }}$ is therefore an upward-biased estimator $\bar{\beta}$; moreover, the greater is $f$, the greater is the endogeneity bias.

Superficially, the earnings model specified by Eq. (5) seems inconsistent with the observation that the cross-sectional relationship between log earnings and schooling is approximately linear. Because of the endogeneity of schooling, however, $S_{i}$ and $\left(b_{i}-\bar{b}\right)$ are positively correlated across the population, leading to a convex relationship between log earnings and schooling in the absence of any concavity in the underlying opportunity locuses. More formally, substitution of (6a) and (6b) into Eq. (5) leads to

$$
\begin{aligned}
\log y_{i} & =a_{0}+\bar{b} S_{i}-1 / 2 k_{1} S_{i}^{2}+\lambda_{0}\left(S_{i}-\bar{S}\right)+\psi_{0} S_{i}\left(S_{i}-\bar{S}\right)+u_{i}+S_{i} v_{i} \\
& =c+\left(\bar{b}+\lambda_{0}-\psi_{0} \bar{S}\right) S_{i}+\left(\psi_{0}-1 / 2 k_{1}\right) S_{i}^{2}+u_{i}+S_{i} v_{i},
\end{aligned}
$$

where $c$ is a constant. If $\mathrm{E}\left[u_{i} \mid S_{i}\right]=\mathrm{E}\left[v_{i} \mid S_{i}\right]=0$ (assumptions which are somewhat stronger than the orthogonality conditions implicit in Eqs. (6a) and (6b)), then Eq. (5') implies that $\mathrm{E}\left[\log y_{i} \mid S_{i}\right]$ is a quadratic function of schooling with second-order coefficient $\left(\psi_{0}-1 / 2 k_{1}\right)$. The empirical relationship between log earnings and schooling will therefore be approximately linear if and only if $k_{1} \approx 2 \psi_{0}$. The bigger is the contribution of variation in $b_{i}$ to the overall variance of schooling, the larger is $\psi_{0}$ and the more convex is the observed relationship between log earnings and schooling. ${ }^{22}$

\subsection{Measurement error}

An important issue in the literature on returns to schooling is the effect of survey measurement error in schooling. As emphasized by Griliches $(1977,1979)$ measurement errors in

\footnotetext{
${ }^{22}$ The observation that the cross-sectional relationship between log earnings and schooling is approximately linear should not be pushed too far. Given the dispersion in residual earnings, a quadratic function of schooling with a non-trivial second order term may well appear linear over the limited range of school outcomes actually observed in any sample.
} 
schooling would be expected to lead to a downward bias in any OLS estimator of the relationship between schooling and earnings. A conventional assumption is that observed schooling $\left(S_{i}{ }^{\circ}\right)$ differs from true schooling $\left(S_{i}\right)$ by an additive error

$S_{i}^{\circ}=S_{i}+\varepsilon_{i}$

with $\mathrm{E}\left[\varepsilon_{i}\right]=0, \mathrm{E}\left[S_{i} \varepsilon_{i}\right]=0$, and $\mathrm{E}\left[\varepsilon_{i}^{2}\right]=\sigma_{\varepsilon}^{2}$. Assuming that Eq. (7) describes the probability limit of an OLS estimator using true schooling, the use of observed schooling will yield an OLS estimator with

$\operatorname{plim}\left(b_{\text {ols }}\right)=R_{0}\left\{\bar{\beta}+\lambda_{0}+\psi_{0} \bar{S}\right\}$,

where

$R_{0} \equiv \operatorname{cov}\left[S_{i}^{\circ}, S_{i}\right] / \operatorname{var}\left[S_{i}^{\circ}\right]=\operatorname{var}\left[S_{i}\right] /\left\{\operatorname{var}\left[S_{i}\right]+\sigma_{\varepsilon}^{2}\right\}$

is the reliability of $S_{i}{ }^{\circ}$, or the signal-to-total-variance ratio of observed schooling. Treating $b_{\text {ols }}$ as an estimator of $\bar{\beta}$, the asymptotic bias is

$\operatorname{Bias}_{\mathrm{ols}}=R_{0}\left(\lambda_{0}+\psi_{0} \bar{S}\right)-\left(1-R_{0}\right) \bar{\beta}$.

Research over the past three decades has generally found that the reliability of selfreported schooling is about $90 \%,{ }^{23}$ suggesting that the second term in this expression is on the order of $-0.1 \bar{\beta}$ in most datasets. Depending on the magnitudes of $\lambda_{0}$ and $\psi_{0} \bar{S}$, this may partially offset the presumably positive biases imparted by the correlations between schooling and the ability components $a_{i}$ and $b_{i}$.

The preceding argument hinges on the assumption that measurement errors in schooling are uncorrelated with true schooling. Since schooling is typically measured as a discrete variable with outcomes ranging between fixed upper and lower limits, however, the errors in reported schooling are probably mean-regressive. ${ }^{24}$ Specifically, individuals with very high levels of schooling cannot report positive errors in schooling, whereas individuals with very low levels of schooling cannot report negative errors in schooling. If the errors in observed schooling measures are negatively correlated with true schooling, the actual reliability of an observed schooling measure may be slightly higher than the estimated reliability inferred from the correlation between two alternative measures of schooling. ${ }^{25}$

${ }^{23}$ See, e.g., Siegel and Hodge (1968), Miller et al. (1995), and Ashenfelter and Rouse (1998). Interestingly, the very limited available evidence on administrative measures of schooling suggests a similar reliability ratio; e.g., Kane et al. (1997); Isacsson (1997).

${ }^{24}$ This point is raised in a recent paper by Kane et al. (1997).

${ }^{25}$ To see this, suppose that there are two measures $x_{1}$ and $x_{2}$ of a true quantity $x$, with $x_{j}=x+e_{j}$, and assume that $\mathrm{E}\left[e_{j} \mid x\right]=-\alpha(x-\mu)$, for $j=1,2$, where $\mu$ is the mean of $x$. Decompose the measurement errors as $e_{j}=$ $-\alpha(x-\mu)+v_{j}$, and assume that the $v_{j}$ 's are independent of each other and $x$, and have equal variances. The reliability of $x_{1}$ is $R=\operatorname{cov}\left[x, x_{1}\right] / \operatorname{var}\left[x_{1}\right]$. Traditionally, reliability is measured by $\rho=\operatorname{cov}\left[x_{1}, x_{2}\right] / \operatorname{var}\left[x_{1}\right]$ (assuming that $x_{1}$ and $x_{2}$ have the same variance). It is straightforward to show that $\rho=(1-\alpha) R$. 


\subsection{Instrumental variables estimates of the return to schooling}

Social scientists have long recognized that the cross-sectional correlation between education and earnings may differ from the true causal effect of education. A standard solution to the problem of causal inference is instrumental variables (IV): a researcher posits the existence of an observable covariate that affects schooling choices but is uncorrelated with (or independent of) the ability factors $a_{i}$ and $b_{i}$. For example, suppose that the marginal cost component $r_{i}$ is linearly related to a set of variables $Z_{i}$ :

$r_{i}=Z_{i} \pi_{1}+\eta_{i}$

In this case the school choice equation becomes

$S_{i}=Z_{i} \pi+\left(b_{i}-\eta_{i}\right) / k=\pi_{0}+Z_{i} \pi+\xi_{i}$,

where $\pi=-\pi_{1} / k$ and $\xi_{i} \equiv\left(b_{i}-\bar{b}-\eta_{i}\right) / k$. In the recent literature much attention has focussed on what might be called institutional sources of variation in schooling, attributable to such features as the minimum school leaving age, tuition costs for higher education, or the geographic proximity of schools. Such institutional factors stand a reasonable chance of satisfying the strict exogeneity assumptions required for a legitimate instrumental variable.

In the presence of heterogeneous returns to education the conditions required to yield an interpretable IV estimator are substantially stronger than those required when the only source of ability bias is random variation in the constant of the earnings equation (i.e., variation in $a_{i}$ ) ${ }^{26}$ Wooldridge (1997) presents a useful analysis that can be directly applied to the system of Eqs. $\left(4^{\prime}\right)$ and (5). Assume for the moment that $k_{1}=0$ in the earnings equation, and consider three additional assumptions on the unobservable components of $\left(4^{\prime}\right)$ and (5):

$\mathrm{E}\left[\eta_{i} \mid Z_{i}\right]=0, \quad \mathrm{E}\left[a_{i} \mid Z_{i}\right]=0, \quad \mathrm{E}\left[\left(b_{i}-\bar{b}\right) \mid Z_{i}\right]=0$,

$\mathrm{E}\left[\left(b_{i}-\bar{b}\right)^{2} \mid Z_{i}\right]=\sigma_{b}^{2}$

$\mathrm{E}\left[\xi_{i} \mid b_{i}, Z_{i}\right]=\rho_{1}\left(b_{i}-\bar{b}\right)$.

Eq. (9a) specifies that the individual-specific heterogeneity components are all mean independent of the instrument $Z . E q .(9 \mathrm{~b})$ states that the second moment of $b_{i}$ is also conditionally independent of $Z_{i}$. Finally, Eq. $(9 \mathrm{c})$ states that the conditional expectation of the unobserved component of optimal school choice $\left(\xi_{i}\right)$ is linear in $b_{i}$. Since $\xi_{i} \equiv\left(b_{i}-\bar{b}-\eta_{i}\right) / k$, a sufficient condition for $(9 \mathrm{c})$ is that $\mathrm{E}\left[\eta_{i} \mid b_{i}, Z_{i}\right]=\rho\left(b_{i}-\bar{b}\right)$, in

\footnotetext{
${ }^{26}$ If the only individual-specific component of ability is $a_{i}$ then Eqs. $\left(4^{\prime}\right)$ and (5) constitute a standard simultaneous equations system and one need only assume $\mathrm{E}\left[a_{i} Z_{i}\right]=\mathrm{E}\left[\eta_{i} Z_{i}\right]=0$. The interpretation of IV in the presence of random coefficients is pursued in a series of papers by Angrist and Imbens (1995) and Angrist et al. (1996). Heckman and Vytlacil (1998) present some results similar to those discussed here.
} 
which case $\rho_{1}=(1-\rho) / k$. This will be true if $b_{i}$ and $\eta_{i}$ have a bivariate normal distribution that is independent of $Z_{i}$, for example.

Under assumptions (9a)-(9c), the conditional expectation of the residual earnings component attributable to heterogeneity in $b_{i}$ is

$$
\begin{aligned}
\mathrm{E}\left[\left(b_{i}-\bar{b}\right) S_{i} \mid Z_{i}\right] & =\mathrm{E}\left[\mathrm{E}\left[\left(b_{i}-\bar{b}\right) S_{i} \mid b_{i}, Z_{i}\right] \mid Z_{i}\right]=\mathrm{E}\left[\left(b_{i}-\bar{b}\right) \mathrm{E}\left[S_{i} \mid b_{i}, Z_{i}\right] \mid Z_{i}\right] \\
& =\mathrm{E}\left[\left(b_{i}-\bar{b}\right) \mathrm{E}\left[Z_{i} \pi+\xi_{i} \mid b_{i}, Z_{i}\right] \mid Z_{i}\right]=\rho_{1} \sigma_{b}^{2} .
\end{aligned}
$$

It follows that

$\mathrm{E}\left[\log y_{i} \mid Z_{i}\right]=a_{0}+\bar{b} Z_{i} \pi+\rho_{1} \sigma_{b}^{2}$.

Thus, the use of $Z_{i}$ as an instrument for education will lead to a consistent estimate of the mean return to schooling $\bar{b}$ (but an inconsistent estimate of $a_{0}$ ). ${ }^{27}$ If earnings are a quadratic function of schooling (i.e., $k_{1}>0$ ) Wooldridge notes that the squared predicted value of schooling from Eq. $\left(4^{\prime}\right)$ can be added to the list of conditioning variables and the previous argument remains valid.

A closely-related alternative to IV estimation of a random coefficients model is a control function approach, first proposed in the schooling context by Garen (1984). In place of Eqs. (9b) and (9c), assume that the conditional expectations of $a_{i}$ and $b_{i}$ are linear in $S_{i}$ and $Z_{i}$ :

$\mathrm{E}\left[a_{i} \mid S_{i}, Z_{i}\right]=\lambda_{1} S_{i}+\lambda_{z} Z_{i}$

$\mathrm{E}\left[b_{i}-\bar{b} \mid S_{i}, Z_{i}\right]==\psi_{1} S_{i}+\psi_{z} Z_{i}$,

As noted in Appendix A, maintaining the assumptions that $\mathrm{E}\left[a_{i} \mid Z_{i}\right]=\mathrm{E}\left[b_{i}-\bar{b} \mid Z_{i}\right]=0$, these conditions are equivalent to assuming

$\mathrm{E}\left[a_{i} \mid S_{i}, Z_{i}\right]=\lambda_{1} \xi_{i}$,

$\mathrm{E}\left[b_{i}-\bar{b} \mid S_{i}, Z_{i}\right]=\psi_{1} \xi_{i}$,

where $\xi_{i}$ is defined in Eq. $\left(4^{\prime}\right)$. It follows immediately that

$\mathrm{E}\left[\log y_{i} \mid S_{i}, Z_{i}\right]=a_{0}+\bar{b} S_{i}-1 / 2 k_{1} S_{i}^{2}+\lambda_{1} \xi_{i}+\psi_{1} \xi_{i} S_{i}$.

The control function approach to estimation of the average return to schooling is to substitute the estimated residual $\breve{\xi}_{i}$ from the reduced form schooling Eq. $\left(4^{\prime}\right)$ in place of $\xi_{i}$ in Eq. (11). Note that the inclusion of $\xi_{i}$ as an additional regressor in the earnings function is numerically equivalent to IV using $Z_{i}$ as an instrument for $S_{i}$. Under the assumption that $\mathrm{E}\left[a_{i} \mid Z_{i}\right]=0$ the addition of $\check{\xi}_{i}$ to the estimated earnings function purges

\footnotetext{
${ }^{27}$ Assumptions (9a) and (9b) are not the only ones that lead to a consistent IV estimator. Wooldridge proposes as an alternative the pair of assumptions: $\mathrm{E}\left[\xi_{i}^{2} \mid Z_{i}\right]=\sigma_{\xi}^{2}$ and $\mathrm{E}\left[\left(b_{i}-\bar{b}\right) \mid \xi_{i}, Z_{i}\right]=\tau \bar{\zeta}_{i}$. The proof of consistency of the IV estimator then proceeds by noting that $\mathrm{E}\left[\left(b_{i}-\bar{b}\right) S_{i} \mid Z_{i}\right]=\mathrm{E}\left[\mathrm{E}\left[\left(b_{i}-\bar{b}\right) S_{i} \mid \xi_{i}, Z_{i}\right] \mid Z_{i}\right]=\tau \sigma_{\bar{\xi}}^{2}$.
} 
the effect of $a_{i}$ on the observed relationship between log earnings and schooling. In general, however, standard IV will not eliminate the influence of $b_{i}$ on the covariance between schooling and earnings, unless $\mathrm{E}\left[\left(b_{i}-\bar{b}\right) S_{i} \mid Z_{i}\right]$ is independent of $Z_{i}$ (as is the case under Wooldridge's assumptions). Under assumption (10b) (or equivalently $\left(10 b^{\prime}\right)$ ), the addition of $\check{\xi}_{i} S_{i}$ as a second control variable is sufficient to eliminate the endogeneity bias arising from the correlation between $b_{i}$ and $S_{i}$. Thus, the control function approach might be viewed as a generalization of instrumental variables.

\subsection{Limitations of instrumental variables}

In the absence of assumptions such as those underlying Eqs. (9) or (10), even an instrumental variables estimator based on an exogenous instrument will not necessarily yield an asymptotically unbiased estimate of the average return to education. To illustrate this point, consider IV estimation using the change in education associated with a "schooling reform" that leads to a proportional reduction in the marginal cost of schooling for students in a specific set of schools (or in a specific cohort). Assume that the joint distribution of abilities and tastes $\left(a_{i}, b_{i}, r_{i}\right)$ is the same for individuals who attended the reformed schools (indexed by $Z_{i}=1$ ) and those who did not (indexed by $Z_{i}=0$ ), but that in the reformed schools the optimal school choice is given by

$S_{i}^{*}=\left(b_{i}-\theta r_{i}\right) / k$,

where $0<\theta<1$. Clearly, differences in $Z_{i}$ will be associated with differences in average levels of schooling. Moreover, by assumption the distributions of ability are the same among students who attended the two sets of schools. In this setting, however, the treatment effect of the school reform is larger for individuals who would have had lower schooling levels in the absence of the reform, causing potential difficulties for the interpretation of an IV estimator based on $Z_{i}$.

Let $r_{i}=\bar{r}+\eta_{i}$, and observe that among the comparison group of individuals who attend the unreformed schools,

$S_{i}=(\bar{b}-\bar{r}) / k+\left(b_{i}-\bar{b}-\eta_{i}\right) / k=\pi_{0}+\xi_{i 0}$,

whereas among the treatment group of individuals who attended reformed schools,

$S_{i}=(\bar{b}-\theta \bar{r}) / k+\left(b_{i}-\bar{b}-\theta \eta_{i}\right) / k=\pi_{1}+\xi_{i 1}$.

Assume that $\mathrm{E}\left[\eta_{i} \mid b_{i}\right]=\rho\left(b_{i}-\bar{b}\right)$. Then

$\mathrm{E}\left[\xi_{0} \mid b_{i}\right]=\rho_{0}\left(b_{i}-\bar{b}\right)$

where $\rho_{0}=(1-\rho) / k$, whereas

$\mathrm{E}\left[\xi_{i 1} \mid b_{i}\right]=\rho_{1}\left(b_{i}-\bar{b}\right)$,

where $\rho_{1}=(1-\theta \rho) / k$. Thus, the correlation between the reduced form schooling error and unobserved ability is different in the treatment and control groups, leading to a viola- 
tion of the assumptions needed for IV or a control function estimator to yield a consistent estimate of the average marginal return to schooling.

The school reform causes a given individual (characterized by the triplet $\left.\left(\mathrm{a}_{i}, \mathrm{~b}_{i}, \eta_{i}\right)\right)$ to increment his or her schooling by an amount

$\Delta S_{i}=\pi_{1}-\pi_{0}+\eta_{i}(1-\theta) / k$.

The (first-order) effect on this individual's earnings is

$\Delta \log y_{i}=\beta_{i} \Delta S_{i}$

where $\beta_{i}$ is $i$ 's marginal return to schooling in the absence of the intervention:

$\beta_{i}=\bar{\beta}+b_{i}-\bar{b}-k_{1}\left(S_{i}-\bar{S}\right)=\bar{\beta}+\left(b_{i}-\bar{b}\right)\left(1-k_{1} / k\right)+\eta_{i} k_{1} / k$.

Using these expressions, the expected earnings differential between individuals in the treatment group and the control group is

$\mathrm{E}\left[\Delta \log y_{i}\right]=\bar{\beta}\left(\pi_{1}-\pi_{0}\right)+k_{1} / k^{2}(1-\theta) \sigma_{\eta}^{2}+\sigma_{b \eta}(1-\theta)\left(1-k_{1} / k\right) / k$,

where expectations are taken with respect to the joint distribution of $\left(a_{i}, b_{i}, \eta_{i}\right)$. The IV estimator of the return to schooling based on the instrument $Z_{i}, b_{\mathrm{iv}}$, has probability limit

$$
\begin{aligned}
\operatorname{plim} b_{\mathrm{iv}} & =\frac{\mathrm{E}\left[\log y_{i} \mid Z_{i}=1\right]-\mathrm{E}\left[\log y_{i} \mid Z_{i}=0\right]}{\mathrm{E}\left[S_{i} \mid Z_{i}=1\right]-\mathrm{E}\left[S_{i} \mid Z_{i}=0\right]} \\
& =\bar{\beta}+\frac{1-\theta}{k\left(\pi_{1}-\pi_{0}\right)}\left\{\sigma_{\eta}^{2} k_{1} / k+\sigma_{b \eta}\left(1-k_{1} / k\right)\right\} .
\end{aligned}
$$

Note that if $\eta_{i}$ is constant for all $i$ (in which case everyone gets the same increment to schooling), then $\sigma_{\eta}^{2}=\sigma_{b \eta}=0$, and the IV estimator is consistent for $\bar{\beta}$. Otherwise, assuming that $\sigma_{b \eta} \leq 0$, so that individuals with higher returns to schooling have higher tastes for schooling or lower discount rates, the IV estimator may be positively or negatively biased relative to $\bar{\beta}$. A positive bias arises because the marginal return to schooling is decreasing in education if $k_{1}>0$ : thus people with initially higher marginal costs of schooling tend to have higher marginal returns to an additional year of schooling. Lang (1993) labelled this phenomenon "discount rate bias". On the other hand, a negative bias arises because people with higher marginal costs of education, who are most affected by the school reform, have lower marginal returns to schooling if $\sigma_{b \eta}<0$. The positive bias is more likely to dominate, the smaller is $\left|\sigma_{b \eta}\right|$ relative to $\sigma_{\eta}^{2}$ and the more concave are individual earnings functions.

To generalize this analysis slightly, suppose that the population can be divided into discrete subgroups of individuals $(g=1,2, \ldots)$ who share common values for the latent ability and cost terms $\left(a_{g}, b_{g}, \eta_{g}\right)$. Consider an intervention (such as a change in the compulsory schooling age) that leads to a change $\Delta S_{g}$ in the mean schooling of group $g$, and let $\beta_{g}$ denote the marginal return to schooling for group $g$ in the absence of the intervention. Finally, suppose that the intervention affects a treatment group of students 
who are otherwise identical to those in a comparison group. In particular, assume that individuals in the treatment group and comparison group with the same latent ability and cost terms would have the same education and earnings in the absence of the intervention, and that the joint distributions of abilities and costs are the same in the two groups. Then an IV estimator of the return to schooling based on an indicator for treatment group status will have probability limit

$\operatorname{plim} b_{\mathrm{iv}}=\frac{\mathrm{E}\left[\beta_{g} \Delta S_{g}\right]}{\mathrm{E}\left[\Delta S_{g}\right]}$

where expectations are taken with respect to the probability distribution of the population across cells. ${ }^{28}$ Note that if $\Delta S_{g} \geq 0$ for all $g$ (which need not be true) then this expression can be interpreted as a weighted average of the marginal returns to education for each group, with weight $\Delta S_{g \cdot{ }^{29}} \mathrm{~A}$ necessary and sufficient condition for $\operatorname{plim} b_{\mathrm{iv}}=\bar{\beta}$ is $\mathrm{E}\left[\beta_{g} \Delta S_{g}\right]=\mathrm{E}\left[\beta_{g}\right] \mathrm{E}\left[\Delta S_{g}\right]$. Among the sufficient conditions for this equality are: (a) $\beta_{g}=$ $\bar{\beta}$ (identical marginal returns for all groups); or (b) $\mathrm{E}\left[\Delta S_{g} \mid \beta_{g}\right]=\Delta S$ (a homogeneous additive treatment effect of the schooling reform). In general, however, if there is some heterogeneity is the distribution of marginal returns to schooling, IV based on an intervention that affects a narrow subgroup of the population may lead to an estimated return to schooling above or below an OLS estimator for the same sample.

Two other aspects of the instrumental variables estimator are worth emphasizing. First, the probability limit of the IV estimator is unaffected by measurement error in schooling. ${ }^{30}$ This in itself will lead to tendency for an IV estimator to exceed the corresponding OLS estimator of the effect of schooling on earnings. Second, the validity of a particular IV estimator depends crucially on the assumption that the instruments are uncorrelated with other latent characteristics of individuals that may affect their earnings. In the case of an IV estimator based on an indicator variable $Z_{i}$, for example, the IV estimator is numerically equal to the difference in mean log earnings between the $Z_{i}=1$ group and the $Z_{i}=0$ group, divided by the corresponding difference in mean schooling. ${ }^{31}$ If the difference in schooling is small, even minor differences in mean earnings between the two groups will be blown up by the IV procedure. If $Z_{i}$ were randomly assigned, as in a true experiment, this would not be a particular problem. In the case of quasi or natural experiments, however, inferences are based on difference between groups of individuals who attended schools at different times, or in different locations, or had differences in other characteristics such as month of

\footnotetext{
${ }^{28}$ This analysis can be generalized by allowing the latent variables to have different distributions among the treatment and comparison groups. This can be handled in principle by "reweighting" the comparison group, although the weights may not be directly observable.

${ }^{29}$ If $\Delta S_{g}$ is dichotomous (so that the change in schooling is either zero or a one unit effect) then the preceding analysis can be placed in the "local average treatment effect" framework developed by Angrist and Imbens (1995). See also Angrist et al. (1996).

${ }^{30}$ This assumes that the instrumental variable is uncorrelated with the measurement error in schooling.

${ }^{31}$ If other covariates are included in the model then the means for each subsample are adjusted for the effects of the covariates.
} 
birth. The use of these differences to draw causal inferences about the effect of schooling requires careful consideration of the maintained assumption that the groups are otherwise identical.

\subsection{Family background}

While some of the most innovative recent research on the value of schooling has used institutional features of the education system to identify the causal effect of schooling, there is a long tradition of using family background information - such as mother's and father's education - to either directly control for unobserved ability or as an instrumental variable for completed education. ${ }^{32}$ Interest in family background is driven by the fact that children's schooling outcomes are very highly correlated with the characteristics of their parents, and in particular with parents' education. ${ }^{33}$ The strength of this correlation is illustrated in Table 2, which reports estimated coefficients from a simple regression of completed education on father's and mother's education, using samples of adult household heads from the 1972-1996 General Social Survey (GSS) ${ }^{34}$ For a variety of subsamples, each additional year of schooling of either parent raises completed education by about 0.2 years, while a rise of 1 year in the parent's average education raises completed schooling by about 0.4 years. Roughly $30 \%$ of the observed variation in education among US adults is explained by parental education. ${ }^{35}$

Despite the strong intergenerational correlation in education, it is far from clear that family background measures are legitimate instrumental variables for completed educa-tion, even if family background has no independent causal effect on earnings. To illustrate this point, assume for the moment that there is no heterogeneity in the return to education (i.e., $b_{i}=\bar{b}$ ) and ignore any concavity in the log earnings function (i.e., assume $k_{1}=0$ ). In this case Eq. (5) becomes

$\log y_{i}=a_{0}+\bar{b} S_{i}+a_{i}$

Consider a linear projection of the unobserved ability component on individual schooling and some measure of family background $\left(F_{i}\right)$ :

$a_{i}=\lambda_{1}\left(S_{i}-\bar{S}\right)+\lambda_{2}\left(F_{i}-\bar{F}\right)+u_{i}^{\prime}$,

This bivariate projection can be compared to the projection of $a_{i}$ on $S_{i}$ alone (i.e., Eq. (6a)) by considering two other auxiliary regressions

32 Griliches (1979) presents a survey of research on family-based models of education and earnings.

${ }^{33}$ See Siebert (1985) for references to some of the literature on family background and education. Ashenfelter and Rouse (1998) show that up to $60 \%$ of the cross-sectional variation in schooling outcomes in their twins sample can be explained by (observable and unobservable) family factors.

${ }^{34}$ The models reported in Table 2 include controls for the age and birth year of the respondents, although the estimated coefficients (and $R$-squared coefficients) are not much different without these controls.

${ }^{35}$ The results in Table 2 are fairly typical of those found in the literature using other samples. If family background is measured by only one parent's education, the coefficient is generally in the range of 0.3-0.4. 
Table 2

Effects of parental education on completed schooling ${ }^{\mathrm{a}}$

\begin{tabular}{|c|c|c|c|c|}
\hline & & Father's education & Mother's education & $R$-squared \\
\hline \multicolumn{5}{|c|}{ By race and gender } \\
\hline 1. & $\begin{array}{l}\text { White men } \\
(N=7330)\end{array}$ & $\begin{array}{c}0.23 \\
(0.01)\end{array}$ & $\begin{array}{c}0.20 \\
(0.01)\end{array}$ & 0.26 \\
\hline 2. & $\begin{array}{l}\text { White women } \\
(N=8547)\end{array}$ & $\begin{array}{c}0.20 \\
(0.01)\end{array}$ & $\begin{array}{c}0.21 \\
(0.01)\end{array}$ & 0.32 \\
\hline 3. & $\begin{array}{l}\text { Black men } \\
(N=705)\end{array}$ & $\begin{array}{c}0.18 \\
(0.03)\end{array}$ & $\begin{array}{c}0.22 \\
(0.04)\end{array}$ & 0.33 \\
\hline 4. & $\begin{array}{l}\text { Black women } \\
(N=1030)\end{array}$ & $\begin{array}{c}0.09 \\
(0.02)\end{array}$ & $\begin{array}{c}0.22 \\
(0.03)\end{array}$ & 0.28 \\
\hline \multicolumn{5}{|c|}{ Men (all races) by birth cohort } \\
\hline 5. & $\begin{array}{l}\text { Born before } 1920 \\
(N=430)\end{array}$ & $\begin{array}{c}0.25 \\
(0.05)\end{array}$ & $\begin{array}{c}0.22 \\
(0.05)\end{array}$ & 0.23 \\
\hline 6. & $\begin{array}{l}\text { Born } 1920-1934 \\
(N=1590)\end{array}$ & $\begin{array}{c}0.26 \\
(0.03)\end{array}$ & $\begin{array}{c}0.24 \\
(0.03)\end{array}$ & 0.22 \\
\hline 7. & $\begin{array}{l}\text { Born 1935-1944 } \\
(N=1785)\end{array}$ & $\begin{array}{c}0.24 \\
(0.02)\end{array}$ & $\begin{array}{c}0.24 \\
(0.02)\end{array}$ & 0.26 \\
\hline 8. & $\begin{array}{l}\text { Born 1945-1954 } \\
(N=2482)\end{array}$ & $\begin{array}{c}0.22 \\
(0.02)\end{array}$ & $\begin{array}{c}0.19 \\
(0.02)\end{array}$ & 0.23 \\
\hline 9. & $\begin{array}{l}\text { Born 1955-1964 } \\
(N=1593)\end{array}$ & $\begin{array}{c}0.26 \\
(0.02)\end{array}$ & $\begin{array}{c}0.11 \\
(0.02)\end{array}$ & 0.23 \\
\hline \multicolumn{5}{|c|}{ Women (all races) by birth cohort } \\
\hline 10. & $\begin{array}{l}\text { Born before } 1920 \\
(N=492)\end{array}$ & $\begin{array}{c}0.21 \\
(0.04)\end{array}$ & $\begin{array}{c}0.25 \\
(0.04)\end{array}$ & 0.29 \\
\hline 11. & $\begin{array}{l}\text { Born } 1920-1934 \\
(N=1936)\end{array}$ & $\begin{array}{c}0.19 \\
(0.02)\end{array}$ & $\begin{array}{c}0.25 \\
(0.02)\end{array}$ & 0.28 \\
\hline 12. & $\begin{array}{l}\text { Born 1935-1944 } \\
(N=2112)\end{array}$ & $\begin{array}{c}0.17 \\
(0.02)\end{array}$ & $\begin{array}{c}0.23 \\
(0.02)\end{array}$ & 0.25 \\
\hline 13. & $\begin{array}{l}\text { Born 1945-1954 } \\
(N=2911)\end{array}$ & $\begin{array}{c}0.19 \\
(0.01)\end{array}$ & $\begin{array}{c}0.18 \\
(0.02)\end{array}$ & 0.25 \\
\hline 14. & $\begin{array}{l}\text { Born 1955-1964 } \\
(N=1960)\end{array}$ & $\begin{array}{c}0.20 \\
(0.01)\end{array}$ & $\begin{array}{c}0.20 \\
(0.02)\end{array}$ & 0.26 \\
\hline
\end{tabular}

"Notes: Dependent variable in all models is years of completed education. Samples include individuals age 24-64 in the 1972-1996 General Social Survey with valid information on their own and both parents' education. Models in rows 1-4 include quadratic functions of respondent's age and birth year, in addition to father's and mother's education. Models in rows 5-14 include only a linear age term.

$F_{i}=\delta_{0}+\delta_{s} S_{i}+e_{1 i}$

$S_{i}=\pi_{0}+\pi_{F} F_{i}+e_{2 i}$

where $e_{1 i}$ is orthogonal to $S_{i}$ and $e_{2 i}$ is orthogonal to $F_{i}$. The conventional omitted variables 
formula implies that the coefficients in Eqs. (6a) and (12) are related by

$\lambda_{0}=\lambda_{1}+\lambda_{2} \delta_{s}$.

Moreover, $\delta_{s}$ and $\pi_{F}$ are related to the correlation coefficient between $S_{i}$ and $F_{i}\left(\rho_{S F}\right)$ by $\delta_{s} \pi_{F}=\rho_{S F}^{2}$.

Using these results it is possible to compare three potential estimators of Eq. $\left(5^{\prime \prime}\right)$ : the OLS estimator from a univariate regression of earnings on schooling $\left(b_{\mathrm{ols}}\right)$; the OLS estimator from a bivariate regression of earnings on schooling and family background $\left(b_{b \mathrm{iv}}\right)$; and the IV estimator using $F_{i}$ as an instrument for $S_{i}\left(b_{\mathrm{iv}}\right)$. The probability limits of these three estimators are

$\operatorname{plim} b_{\mathrm{ols}}=\bar{b}+\lambda_{0}=\bar{b}+\lambda_{1}+\lambda_{2} \rho_{S F}^{2} / \pi_{F}$

$\operatorname{plim} b_{\mathrm{biv}}=\widetilde{b}+\lambda_{1}$

$\operatorname{plim} b_{\mathrm{iv}}=\operatorname{cov}\left[\log y_{i}, F_{i}\right] / \operatorname{cov}\left[S_{i}, F_{i}\right]=\bar{b}+\lambda_{1}+\lambda_{2} / \pi_{F}$.

In addition, the probability limit of the coefficient on $F_{i}$ in the bivariate regression is just $\lambda_{2}{ }^{36}$ Assuming that $\lambda_{1} \geq 0, \lambda_{2} \geq 0$, and $\pi_{F}>0$,

$\bar{b} \leq \operatorname{plim} b_{\text {biv }} \leq \operatorname{plim} b_{\text {ols }} \leq \operatorname{plim} b_{\text {iv }}$.

If $a_{i}$ and $S_{i}$ are uncorrelated, controlling for $F_{i}$, then $\lambda_{1}=0$ and the bivariate OLS estimator is consistent for $\bar{b}$. Otherwise all three estimators are likely to be upward biased, with bigger biases in the univariate OLS and IV estimators than in the bivariate estimator unless $\lambda_{2}=0 .^{37}$

This analysis is readily extended to the case in which $b_{i}$ varies across individuals. Assume that earnings are given by Eq. (5) and consider the projection of $b_{i}$ on $S_{i}$ and $F_{i}$ :

$b_{i}-\bar{b}=\psi_{1}\left(S_{i}-\bar{S}\right)+\psi_{2}\left(F_{i}-\bar{F}\right)+v_{i}^{\prime}$.

As with the coefficients $\lambda_{0}$ and $\lambda_{1}$, the coefficients $\psi_{0}$ in Eq. (6b) and $\psi_{1}$ in Eq. (14) are related by

$\psi_{0}=\psi_{1}+\psi_{2} \delta_{s}=\psi_{1}+\psi_{2} \rho_{S F}^{2} / \pi_{F}$

Using Eq. (A.3) of the Appendix, and assuming that $b_{i}, S_{i}$, and $F_{i}$ have a jointly symmetric distribution, it is straightforward to show that

$\operatorname{plim} b_{\mathrm{ols}}=\bar{\beta}+\lambda_{0}+\psi_{0} \bar{S}=\bar{\beta}+\lambda_{1}+\psi_{1} \bar{S}+\left(\lambda_{2}+\psi_{2} \bar{S}\right) \rho_{S F}^{2} / \pi_{k}$,

${ }^{36}$ If $F_{i}$ has an independent causal effect $\gamma$ on earnings then Eq. $\left(5^{\prime \prime}\right)$ includes a term $\gamma F_{i}$. In this case the probability limit of the regression coefficient of $F_{i}$ is $\gamma+\lambda_{2}$, and $p$ lim $b_{\text {iv }}$ includes a component equal to $\gamma / \pi_{F}$.

${ }^{37}$ Suppose that family background is measured by the average of mother's and father's education. The results in Table 2 suggest that $\pi_{\mathrm{F}} \approx 0.4$ and $\rho_{\mathrm{SF}}^{2} \approx 0.3$, implying that the univariate OLS estimator will exceed the bivariate OLS by about $0.75 \lambda_{2}$, while the IV estimator will exceed the bivariate OLS by $2.5 \lambda_{2}$. 
$\operatorname{plim} b_{\text {biv }}=\bar{\beta}+\lambda_{1}+\psi_{1} \bar{S}$,

$\operatorname{plim} b_{\mathrm{iv}}=\bar{\beta}+\lambda_{1}+\psi_{1} \bar{S}+\left(\lambda_{2}+\psi_{2} \bar{S}\right) / \pi_{F}$.

Moreover, the probability limit of the coefficient on $F_{i}$ in the bivariate regression is $\lambda_{2}+\psi_{2} \bar{S}$. In the presence of heterogeneity in $b_{i}$ one can effectively reinterpret $\lambda_{1}$ as $\left(\lambda_{1}+\psi_{1} \bar{S}\right)$ and $\lambda_{2}$ as $\left(\lambda_{2}+\psi_{2} \bar{S}\right)$. Assuming that $\lambda_{1}+\psi_{1} \bar{S} \geq 0, \lambda_{2}+\psi_{2} \bar{S} \geq 0$, and $\pi_{F}>0$, the probability limits of the three estimators continue to satisfy the inequalities

$\bar{\beta} \leq \operatorname{plim} b_{\text {biv }} \leq \operatorname{plim} b_{\text {ols }} \leq \operatorname{plim} b_{\text {iv }}$.

In summary, unless $\lambda_{1}=\lambda_{2}=\psi_{1}=\psi_{2}=0$ in the projection equations for the intercept and slope components of individual ability $a_{i}$ and $b_{i}$, family background is not a legitimate instrument for schooling, even if family background has no direct causal effect on earnings. The addition of controls for family background may reduce the biases in the measured return to education, but may still lead to an upward-biased estimate of the average marginal return to schooling unless all of the unobserved ability components are absorbed by the family background controls (i.e., unless $\lambda_{1}=\psi_{1}=0$ ). Finally, notice that in the special case where $\lambda_{1}+\psi_{1} \bar{S}=\lambda_{2}+\psi_{2} \bar{S}$, the upward bias in the estimated schooling coefficient from a bivariate model that controls for family background is equal to the probability limit of the coefficient on the family background variable itself. Under these circumstances, one can recover an unbiased estimate of the average marginal return to schooling by subtracting the family background coefficient from the own-schooling coefficient. This is equivalent to a "within-family" estimator, and will be discussed in more detail in the next section.

The preceding analysis assumes that true schooling is observable. In the more realistic case in which only a noisy measure of educational attainment is available, a comparison between the three estimators must take account of the differential impact of measurement errors on the univariate OLS, bivariate OLS, and IV estimators. Let $R_{0}$ represent the reliability of measured education and assume for the moment that $F_{i}$ is measured without error. As noted earlier, the univariate OLS estimator is attenuated by the factor $R_{0}$ :

$\operatorname{plim} b_{\mathrm{ols}}=R_{0}\left[\bar{\beta}+\lambda_{1}+\psi_{1} \bar{S}+\left(\lambda_{2}+\psi_{2} \bar{S}\right) \rho_{S F}^{2} / \pi_{F}\right]$.

The addition of $F_{i}$ to the earnings model will tend to lead to greater attenuation of the coefficient on measured schooling, since some part of true education can be inferred from $F_{i}$. As shown in Appendix A, the bivariate OLS estimator is attenuated by a factor $R_{1}$ :

$\operatorname{plim} b_{\mathrm{biv}}=R_{1}\left[\vec{\beta}+\lambda_{\mathrm{I}}+\psi_{1} \bar{S}\right]$,

where $R_{1}=\left(R_{0}-\rho_{S F}^{2}\right) /\left(1-\rho_{S F}^{2}\right)<R_{0}$. For example, if $R_{0} \approx 0.9$ and $\rho_{S F}^{2} \approx 0.3$ then $R_{1} \approx 0.85$. In contrast to either OLS estimator, the IV estimator is unaffected by measurement error. Thus, if $F_{i}$ is measured without error, measurement errors in schooling will tend to reinforce the expected ranking of the univariate OLS, bivariate OLS, and IV 
estimators by introducing the greatest attenuation bias in the bivariate OLS estimator, an intermediate bias in the univariate OLS estimator, and none in the IV estimator.

In many datasets family background information is collected from children or gathered retrospectively from older adults. In either case, one might expect $F_{i}$ to contain substantial reporting errors. Indeed, Ashenfelter and Rouse (1998, Appendix 1) find that the reliability of twins' reports of their mother's education is about $80 \%$, compared to a $90 \%$ reliability ratio for their own education. The presence of measurement errors in $F_{i}$ creates a more complex expression for the probability limit of the bivariate OLS estimator. Specifically, the bivariate measurement error formula presented in the Appendix implies that

$\operatorname{plim} b_{\text {biv }}=R_{1}\left[\bar{\beta}+\lambda_{1}+\psi_{1} \bar{S}\right]+\left(\lambda_{2}+\psi_{2} \bar{S}\right)\left(1-R_{F}\right) \rho_{S F}^{2} /\left(\pi_{F}\left(1-\rho_{S F}^{2}\right)\right)$,

where $R_{F}$ is the reliability of measured family background. The second term in this expression is 0 if the true coefficient of family background in the bivariate model is 0 (i.e., if $\lambda_{2}+\psi_{2} \bar{S}=0$ ), or if $R_{F}=1$. If the true coefficient of $F_{i}$ is positive and $\pi_{F}>0$, however, then measurement errors in $F_{i}$ induce a positive bias in the schooling coefficient that may partially offset the direct attenuation effect of measurement error in $S_{i}$. For example, if $R_{F} \approx 0.8, \rho_{S F}^{2} \approx 0.3$, and $\pi_{F} \approx 0.4$, the second term is on the order of $20 \%$ of the true coefficient of family background.

\subsection{Models for siblings and twins}

An alternative to the instrumental variables approach to the problem of causal inference is to study education and earnings outcomes for siblings, twins, or father-son/motherdaughter pairs. The key idea behind this strategy is that some of the unobserved differences that bias a cross-sectional comparison of education and earnings are reduced or eliminated within families. ${ }^{38}$ For example, suppose that two observations (indexed by $j=1$ or 2 ) are available for each family (indexed by $i$ ), and that the earnings of person $j$ from family $i$ are generated by

$\log y_{i j}=a_{0}+\bar{b} S_{i j}-1 / 2 k_{1} S_{i j}+a_{i j}+\left(b_{i j}-\bar{b}\right) S_{i j}$.

A "pure family effects" model is one in which $a_{i j}=a_{i}$ and $b_{i j}=b_{i}$. Consider the linear projections of $a_{i}$ and $b_{i}-\bar{b}$ on the observed schooling outcomes of the two family members:

$a_{i}=\lambda_{1}\left(S_{i 1}-\bar{S}_{1}\right)+\lambda_{2}\left(S_{i 2}-\bar{S}_{2}\right)+u_{i}$

$b_{i}-\bar{b}=\psi_{1}\left(S_{i 1}-\bar{S}_{1}\right)+\psi_{2}\left(S_{i 2}-\bar{S}_{2}\right)+v_{i}$

Assuming that $b_{i}, S_{i 1}$, and $S_{i 2}$ have a jointly symmetric distribution, Eq. (A.3) in Appendix A implies that the observed earnings outcomes of the family members are related to their

\footnotetext{
${ }^{38}$ Of course a within-family estimator can be given an IV interpretation: the instrument for schooling is the deviation of an individual's schooling from the average for his or her family.
} 
schooling levels by

$$
\begin{aligned}
& \log y_{i 1}=c_{1}+\left(\bar{\beta}+\lambda_{1}+\psi_{1} \bar{S}_{1}\right) S_{i 1}+\left(\lambda_{2}+\psi_{2} \bar{S}_{1}\right) S_{i 2}+e_{i 1}, \\
& \log y_{i 2}=c_{2}+\left(\lambda_{1}+\psi_{1} \bar{S}_{2}\right) S_{i 1}+\left(\bar{\beta}+\lambda_{2}+\psi_{2} \bar{S}_{1}\right) S_{i 2}+e_{i 1},
\end{aligned}
$$

where $c_{1}$ and $c_{2}$ are constants and the residuals $e_{i j}$ are orthogonal to both $S_{i 1}$ and $S_{i 2}$. Eqs. (17a) and (17b) constitute a system of seemingly unrelated regressions. ${ }^{39}$ Since there are no exclusion restrictions, the system can be estimated efficiently by applying OLS one equation at a time. Alternatively, one can construct the within-family difference in $\log$ earnings $\Delta \log y_{i} \equiv \log y_{i 1}-\log y_{i 2}$, and consider a model of the form

$\Delta \log y_{i}=\mu_{1} S_{i 1}+\mu_{2} S_{i 2}+e_{i}$

Numerically, OLS estimates of the coefficients of (18) will be equal to the differences in the corresponding OLS estimates of the coefficients in (17a) and (17b). ${ }^{40}$

The attractiveness of the "pure family effects" model arises from the fact that one can potentially recover estimates of $\bar{\beta}$ from the differences in the coefficients of Eqs. (17), or from the coefficients of the differenced Eq. (18). For example, suppose there is no heterogeneity in $b_{i}$. In this case $\psi_{1}=\psi_{2}=0$ in Eqs. (17a) and (17b), and therefore the coefficients of Eq. (18) satisfy

$\operatorname{plim} \mu_{1}=\operatorname{plim}-\mu_{2}=\bar{\beta}$.

A test of the hypothesis $\mu_{1}=-\mu_{2}$ therefore provides a specification test of the "pure family effects" model when heterogeneity in the education slopes $b_{i}$ is ignored. $^{41}$

A "pure family effects" model is particularly plausible for identical twins, since identical twins share genetics and almost always share the same family background environment. For identical twins, it also seems natural to impose the symmetry conditions $\lambda_{1}=\lambda_{2}=\lambda, \psi_{1}=\psi_{2}=\psi$, and $\bar{S}_{1}=\bar{S}_{2}=\bar{S}$, since the identity of specific twins is arbitrary. With these simplifications Eqs. (17a) and (17b) reduce to

$$
\begin{aligned}
\log y_{i 1} & =c_{1}+(\bar{\beta}+\lambda+\psi \bar{S}) S_{i 1}+(\lambda+\psi \bar{S}) S_{i 2}+e_{i 1} \\
& =c_{1}+\bar{\beta} S_{i 1}+(\lambda+\psi \bar{S})\left(S_{i 1}+S_{i 2}\right)+e_{i 1}
\end{aligned}
$$

\footnotetext{
${ }^{39}$ A system of equations like (17a) and (17b) is sometimes called a "correlated random effects" specification. The idea of projecting the unobservable residual component (i.e., the family effect) on the observed outcomes of the pair and then substituting the projection equation back into the earnings equation was popularized by Chamberlain (1982).

${ }^{40}$ If other covariates $X_{i j}$ are included in the model then the first-differenced model has to contain $X_{i 1}$ and $X_{i 2}$ in order for the "adding up" condition to hold.

${ }^{41}$ Such tests have been widely used in other applications of the correlated random effects model: e.g., Jakubson (1988)
} 


$$
\begin{aligned}
\log y_{i 2} & =c_{2}+(\lambda+\psi \bar{S}) S_{i 1}+(\bar{\beta}+\lambda+\psi \bar{S}) S_{i 2}+e_{i 2} \\
& =c_{2}+\bar{\beta} S_{i 2}+(\lambda+\psi \bar{S})\left(S_{i 1}+S_{i 2}\right)+e_{i 2} .
\end{aligned}
$$

These equations express log earnings of a particular twin in terms of his or her own education and the total (or average) education of the pair. ${ }^{42}$ Under the assumptions of a "pure family effects" specification, all of the biases arising from the correlations between unobserved ability and schooling are loaded onto the coefficient associated with the total or average education of the family, and the own-schooling coefficient provides an unbiased estimate of the average marginal return to schooling. (This estimate is numerically equivalent to subtracting the estimated sibling education coefficient from the own schooling coefficient). Note that if the pure family effects and symmetry assumptions are satisfied, one can estimate $\bar{\beta}$ with data on earnings for only one twin, provided that both twin's schooling levels are known. ${ }^{43}$

In the case of siblings or father-son pairs it may be less plausible that individuals from the same family have exactly the same ability parameters. For example, older siblings may be treated differently than younger ones, leading to differences in their potential labor market outcomes. ${ }^{44}$ The assumptions of a "pure family effects" model can be relaxed as follows. Consider the linear projections,

$$
\begin{aligned}
& a_{i 1}=\lambda_{11}\left(S_{i 1}-\bar{S}_{1}\right)+\lambda_{12}\left(S_{i 2}-\bar{S}_{2}\right)+u_{i 1}, \\
& a_{i 2}=\lambda_{21}\left(S_{i 1}-\bar{S}_{1}\right)+\lambda_{22}\left(S_{i 2}-\bar{S}_{2}\right)+u_{i 1}, \\
& b_{i 1}-\bar{b}=\psi_{11}\left(S_{i 1}-\bar{S}_{1}\right)+\psi_{12}\left(S_{i 2}-\bar{S}_{2}\right)+v_{i 1}, \\
& b_{i 2}-\bar{b}=\psi_{21}\left(S_{i 1}-\bar{S}_{1}\right)+\psi_{22}\left(S_{i 2}-\bar{S}_{2}\right)+v_{i 2},
\end{aligned}
$$

where $u_{i j}$ and $v_{i j}$ are orthogonal to $S_{i 1}$ and $S_{i 2}$. For randomly-ordered siblings or fraternal twins it is natural to assume that the projection coefficients satisfy the symmetry restrictions: $\lambda_{11}=\lambda_{22}, \lambda_{12}=\lambda_{21}, \psi_{11}=\psi_{22}$, and $\psi_{12}=\psi_{21}$, although for father-son or motherdaughter pairs these assumptions are less appealing. ${ }^{45}$ Substituting these equations into the earnings model (15) and considering the linear projection onto the observed schooling variables leads to a generalized version of Eqs. (17a) and $(17 \mathrm{~b}):^{46}$

$\log y_{i 1}=c_{1}+\tau_{11} S_{i 1}+\tau_{12} S_{i 2}+e_{i 1}$,

\footnotetext{
${ }^{42}$ Similar equations are derived by Ashenfelter and Rouse (1998).

${ }^{43}$ Exchangeability arguments suggest that symmetry should hold for a random ordering of twins in each family. However, if the "twin 1" sample is conditioned on employment and some of the individuals in the "twin 2 " sample do not work, the ordering is no longer random, and symmetry might not be a valid restriction.

${ }^{44}$ See Kessler (1991). Kessler concludes that birth order has little or no effect on economic outcomes once family size is properly accounted for.

${ }^{45}$ For father-son pairs, Ashenfelter and Zimmerman (1997) propose a slightly generalized model in which $\lambda_{2 j}=\alpha \lambda_{i j}$. They ignore heterogeneity in $b_{i}$.
} 
$\log y_{i 2}=c_{2}+\tau_{21} S_{i 1}+\tau_{22} S_{i 2}+e_{i 2}$,

where

$\tau_{11}=\bar{\beta}+\lambda_{11}+\psi_{11} \bar{S}_{1}, \quad \tau_{12}=\lambda_{12}+\psi_{12} \bar{S}_{1}$,

$\tau_{21}=\lambda_{21}+\psi_{21} \bar{S}_{2}, \quad \tau_{22}=\bar{\beta}+\lambda_{22}+\psi_{22} \bar{S}_{2}$.

Clearly $\bar{\beta}$ is not identifiable from the seemingly unrelated regression coefficients in (20a) and (20b) even with the within-family symmetry assumptions, although if $\psi_{i j}=0$ or $\bar{S}_{1}=$ $\bar{S}_{2}$ then symmetry imposes two linear restrictions on the coefficients $\left(\tau_{11}=\tau_{22}\right.$ and $\left.\tau_{21}=\tau_{12}\right)$.

Nevertheless, it may be possible to place an upper bound on the average marginal return to schooling using data on fraternal twins or siblings. Specifically, suppose that $\lambda_{11} \geq \lambda_{12}$ and $\psi_{11} \geq \psi_{12}$; loosely, these assumptions mean that individual 1's own schooling is more informative about his or her ability than individual 2's schooling. ${ }^{47}$ In this case,

$$
\begin{aligned}
\operatorname{plim} \tau_{11}-\tau_{12} & =\bar{\beta}+\lambda_{11}+\psi_{11} \bar{S}_{1}-\lambda_{12}-\psi_{12} \bar{S}_{1} \\
& =\bar{\beta}+\left(\lambda_{11}-\lambda_{12}\right)+\left(\psi_{11}-\psi_{12}\right) \bar{S}_{1} \\
& \geq \bar{\beta}
\end{aligned}
$$

so an upper bound estimator of $\bar{\beta}$ is $\tau_{11}-\tau_{12}$, the difference between the own-schooling effect and the other-family-member's-schooling effect in an equation for one family member's earnings. ${ }^{48}$ Mechanically, this difference is equal to the coefficient of ownschooling when average family schooling is included in the regression, as in Eq. $\left(17 a^{\prime}\right){ }^{49}$

Unfortunately, there is no guarantee that this bound is tighter than the bound implied by the cross-sectional OLS estimator. In other words, it is possible that the OLS estimator has a smaller upward bias than the within family estimator based on Eq. (17a). A necessary and sufficient condition for the within-family estimator to have a smaller asymptotic bias is

$\left|\lambda_{0}+\psi_{0} \bar{S}_{1}\right|>\left|\lambda_{11}-\lambda_{12}+\left(\psi_{11}-\psi_{12}\right) \bar{S}_{1}\right|$

\footnotetext{
${ }^{46}$ Note that I am continuing to assume that $\left(b_{i j}, S_{1}, S_{i 2}\right)$ have a jointly symmetric distribution.

${ }^{47}$ Assumptions on the relative magnitudes of the projection coefficients are most natural if $S_{i 1}$ and $S_{i 2}$ have the same variances. In that case, $\lambda_{11}-\lambda_{12}=A\left(\operatorname{cov}\left[a_{i 1}, S_{i 1}\right]-\operatorname{cov}\left[a_{i 1}, S_{i 2}\right]\right)$ for some positive coefficient $A ;$ a similar expression holds for $\psi_{11}-\psi_{12}$.

${ }^{48}$ If the "pure family effects" and symmetry assumptions are satisfied then $\operatorname{plim}\left(\tau_{11}-\tau_{12}\right)=\bar{\beta}$.

${ }^{49} \mathrm{It}$ is also closely related to the coefficient of the difference in schooling in an inter-family differenced model: $\Delta \log y_{i}=\tau_{\Delta} S_{i}+\Delta e_{i}$. This specification is appropriate if the symmetry restrictions $\lambda_{11}=\lambda_{22}, \lambda_{12}=\lambda_{21}$, $\psi_{11}=\psi_{22}, \psi_{12}=\psi_{21}$, and $\bar{S}_{1}=\bar{S}_{2}$ are valid, in which case $\tau_{11}=\tau_{22}$ and $\tau_{21}=\tau_{12}$. For example, in the case of same-sex fraternal twins the identity of the individual twins is arbitrary so an "exchangeability" argument suggests that symmetry should hold. Under this assumption $\operatorname{plim} \tau_{\Delta}=\operatorname{plim}\left(\tau_{11}-\tau_{21}\right)=\operatorname{plim}\left(\tau_{11}-\tau_{12}\right)$, although the estimate of $\tau_{\Delta}$ is not mechanically equal to the difference in the estimates of $\tau_{11}$ and $\tau_{12}$.
} 
where $\lambda_{0}$ and $\psi_{0}$ are the projection coefficients defined in Eqs. (6a) and (6b). To illustrate the issues underlying the comparison between the OLS and within-family estimators, ignore heterogeneity in the earnings function intercepts $a_{i j}$, so that the relative asymptotic biases of the OLS and within-family estimators depend on the comparison between $\psi_{0}$ and $\psi_{11}-\psi_{12}$. Suppose first that the marginal costs of schooling are identical for members of the same family $\left(r_{i j}=r_{i}\right)$ but that ability has no family component (i.e., $\operatorname{cov}\left[b_{i 1}, b_{i 2}\right]=0$ ). In this case all of the schooling differences within families are due to differences in ability, whereas across the population as a whole only a fraction $f=\sigma_{b}^{2} /\left(\sigma_{b}^{2}+\sigma_{r}^{2}\right)$ of the variance of schooling is attributable to ability. As noted earlier, the endogeneity bias component in the cross-sectional OLS estimator is $\psi_{0}=k f$. Using Eq. (19) it is easy to show that $\psi_{11}=$ $k f /\left(1-(1-f)^{2}\right)$ and $\psi_{12}=-\mathrm{kf}(1-\mathrm{f}) /\left(1-(1-\mathrm{f})^{2}\right)$. Hence $\psi_{11}-\psi_{12}=k$, implying that the within-family estimator has a greater endogeneity bias than the cross-sectional estimator.

At the other extreme, suppose that abilities are the same for members of the same family $\left(b_{i j}=b_{i}\right)$ but that tastes are uncorrelated within families. In this case schooling differences within families are due entirely to differences in tastes, even though in the population as a whole a fraction $f$ of the variance in schooling is due to differences in ability. Hence the within-family estimator is free of endogeneity biases whereas the OLS estimator has an endogeneity bias component $\psi_{0}=k f$. More generally, the relative magnitudes of the endogeneity biases in the within-family and cross-sectional estimators depend on the relative contributions of ability differentials to the within-family and cross-sectional variances of schooling outcomes. ${ }^{50} \mathrm{~A}$ within-family estimator will have a smaller bias if and only if ability differences are less important determinants of schooling within families than across the population as a whole.

Measurement error concerns play a fairly important role in the interpretation of estimates from sibling and family models. This is especially true in studies of identical twins, who tend to have very highly correlated education outcomes. For example, consider the estimation of Eq. (17a) using noisy measures of schooling for both twins. The multivariate measurement error formula implies that the probability limit of the coefficient on ownschooling is

$\bar{\beta} \frac{R_{0}-\rho^{2}}{1-\rho^{2}}+(\lambda+\psi \bar{S}) \frac{1-R_{0}}{1-\rho^{2}} \times \frac{\operatorname{cov}\left[S_{i 1}, S_{i 1}+S_{i 2}\right]}{\operatorname{var}\left[S_{i 1}\right]}$,

where $R_{0}$ is the reliability of measured schooling and $\rho$ is the correlation of twin's school ing. Assuming that $R_{0} \approx 0.9$ and $\rho \approx 0.75$ (see e.g., Ashenfelter and Rouse, 1998), this formula implies that the probability limit of the own schooling coefficient is roughly $0.8 \vec{\beta}+0.3(\lambda+\psi \vec{S})$.

Much of the twins literature focusses on estimation of a within-family differences model:

\footnotetext{
${ }^{50}$ A similar argument applies to the asymptotic biases in the two estimators associated with the correlation between $a_{i j}$ and $S_{i j}$.
} 
$\Delta \log y_{i}=\tau_{\Delta} \Delta S_{i}+\Delta e_{i}$

Assuming that the "pure family effects" assumptions are satisfied and ignoring measurement error,

$\operatorname{plim} \tau_{\Delta}=\bar{\beta}$,

as can be seen by differencing Eqs. (20a) and (20b). The within-family differenced estimator is particularly susceptible to measurement error, however, since differencing within families removes much of the true signal in education. In particular, if the reliability of observed schooling is $R_{0}$ and the correlation between family members' schooling is $\rho$ then the reliability of the observed difference in schooling is

$R_{\Delta}=\frac{R_{0}(1-\rho)}{1-\rho R_{0}}$.

When $R_{0} \approx 0.9$ and $\rho \approx 0.75$, for example, $R_{\Delta} \approx 0.7$, implying a $30 \%$ attenuation bias in the OLS estimate of $\tau_{\Delta}$ for identical twins. Among fraternal twins the correlation of schooling is lower: Ashenfelter and Krueger (1994) and Isacsson (1997) both estimate a correlation for fraternal twins of about 0.55 . Assuming $R_{0} \approx 0.9$ and $\rho \approx 0.55, R_{\Delta} \approx 0.8$, so one would expect a $20 \%$ attenuation bias in the OLS estimate of $\tau_{\Delta}$ for fraternal twins.

\subsection{Summary}

Table 3 summarizes some of the key models, assumptions, and estimating equations that are useful in interpreting the returns to schooling literature. One estimation strategy not included in the table is instrumental variables based on a comparison between a quasiexperimental treatment group and a comparison group when the treatment has potentially different effects on the schooling attainment of different subgroups of the population. As noted above, under ideal conditions such an estimator will recover a weighted average of the marginal returns to education for different subgroups, where the weight applied to each subgroup is the change in schooling induced by the treatment. This weighted average may be above or below the average marginal return to education, depending on the nature of the intervention and the extent of heterogeneity in marginal returns.

Among the implications of the results summarized in Table 3 are:

1. The OLS estimator has two ability biases relative to the average marginal return to education $(\bar{\beta})$ : one attributable to the correlation between schooling and the intercept of the earnings function $\left(a_{i}\right)$, the other attributable to the correlation between schooling and the slope of the earnings function $\left(b_{i}\right)$. The latter is unambiguously positive, but may be small in magnitude if the heterogeneity in returns to education is small (or if people lack perfect foresight about their abilities).

2. The necessary conditions for IV or control function estimators to yield a consistent estimate of $\bar{\beta}$ in the presence of heterogeneity in the returns to education are fairly strict. Plausible sources of exogenous variation in education choices (such as shifts in 


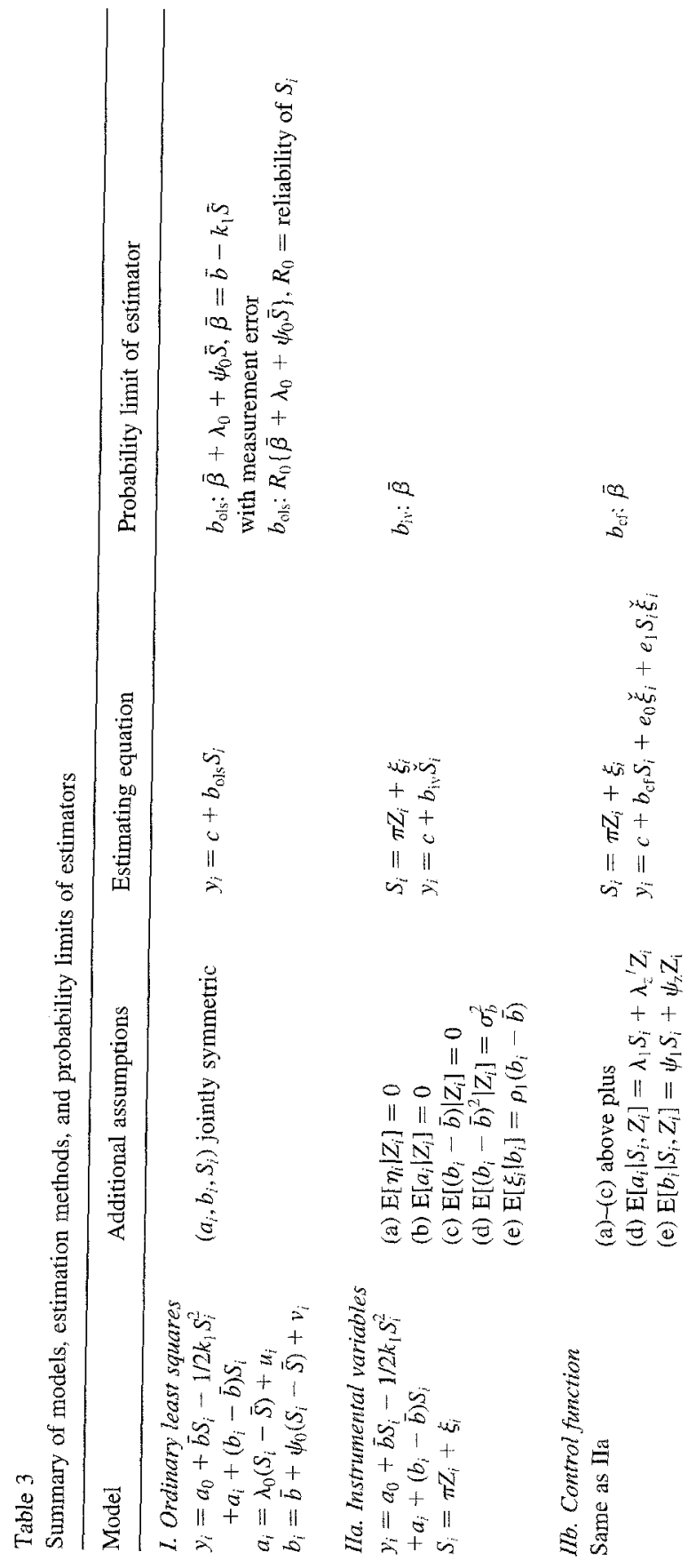




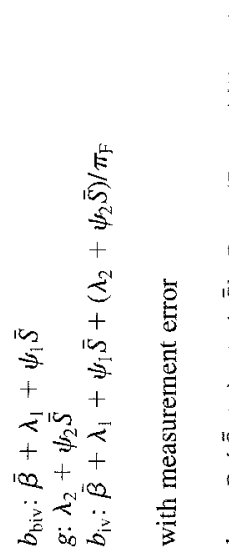

2
1
0
2
1
5
11
5
5
0
5
+
2
+
0
0
0
0
5
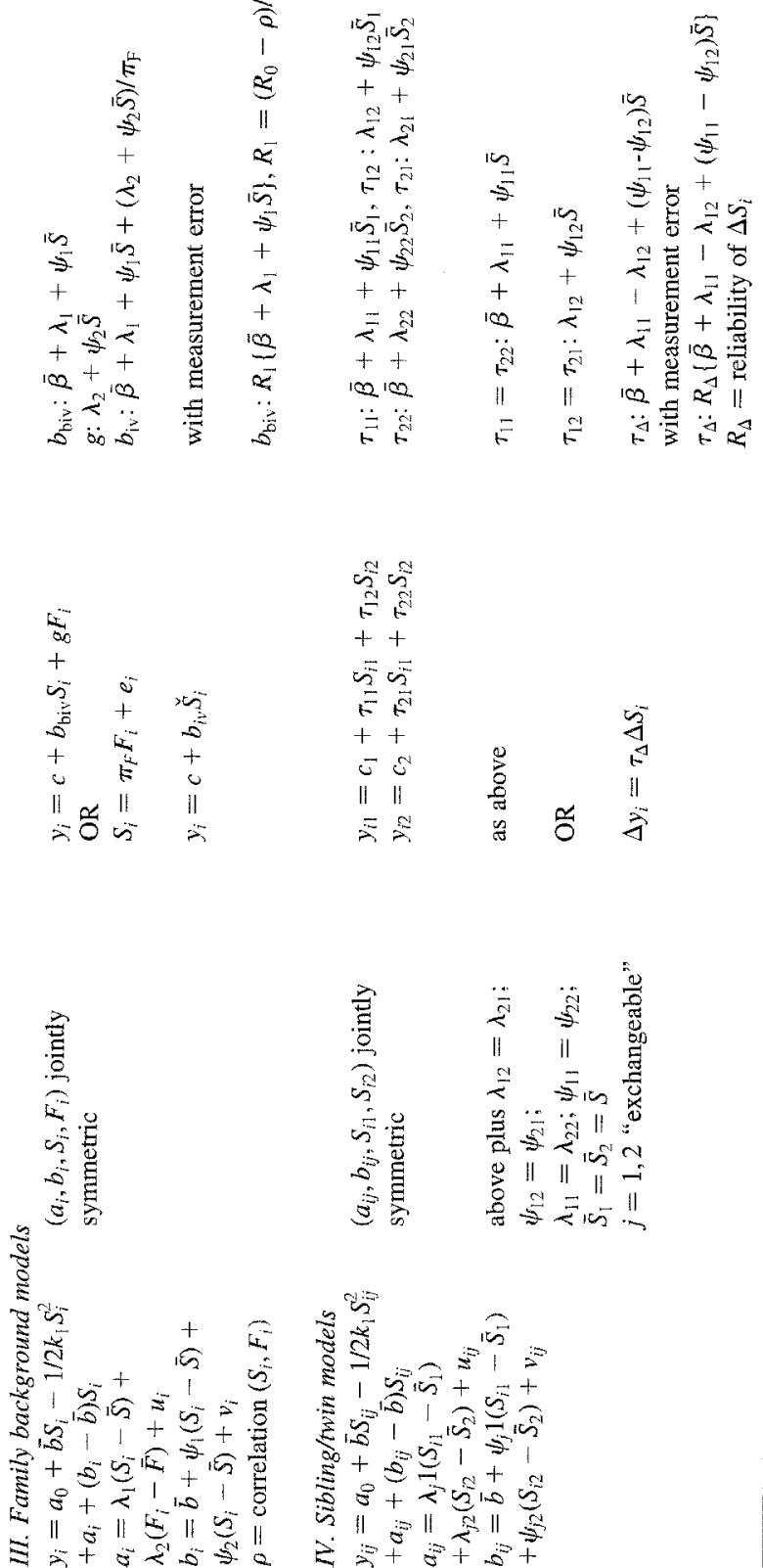
the cost of schooling) may not satisfy these conditions, in which case IV will recover a weighted average of marginal returns for the affected subgroups.

3. If the OLS estimator is upward-biased by unobserved ability, one would expect an IV estimator based on family background to be even more upward-biased.

4. If twins or siblings have identical abilities (and the distributions of abilities among twins are the same as those in the population as a whole) then a within-family estimator will recover an asymptotically unbiased estimate of the average marginal return to education. Otherwise, a within-family estimator may be more or less biased by unobserved ability effects than the corresponding cross-sectional OLS estimator, depending on the relative fraction of the variance in schooling attributable to ability differences within families versus across the population.

5. Measurement error biases are potentially important in interpreting the estimates from different procedures. Conventional OLS estimates are probably downward-biased by about 10\%; OLS estimates that control for family background (or the education of a sibling) may be downward-biased by $15 \%$ or more; and within-family differenced estimates may be downward-biased by $20-30 \%$, with the upper range more likely for identical twins.

\section{A selective review of recent empirical studies}

I now turn to a selective review of the recent literature on estimating the return to schooling. I summarize three sets of findings: instrumental variables estimates of the return to education based on institutional features of the education system; estimates based on either controlling for family background or using family background as an instrument for schooling; and estimates based on the schooling and earnings of twins. I also briefly review recent efforts to model observable heterogeneity in the returns to schooling. One strand of literature that I do not consider are studies of the return to schooling that attempt to control for ability using observed test scores. Some of the subtle issues involved in developing a causal framework for the interpretation of test scores, schooling outcomes, and earnings are considered in Griliches (1977, 1979), Chamberlain (1977) and Chamberlain and Griliches (1975, 1977).

\subsection{Instrumental variables based on institutional features of the school system}

One of the most important new directions of research in the recent literature on schooling is the use of institutional features of the schooling system as a source of credible identifying information for disentangling the causal effects of schooling. ${ }^{51}$ Table 4 summarizes seven recent studies that estimate the return to schooling using instrumental variables

\footnotetext{
${ }^{51}$ This idea is also proving useful in studies of the effect of school quality. For example, Angrist and Lavy (1997) use information on maximum class size to identify the effect of class size on student achievement.
} 


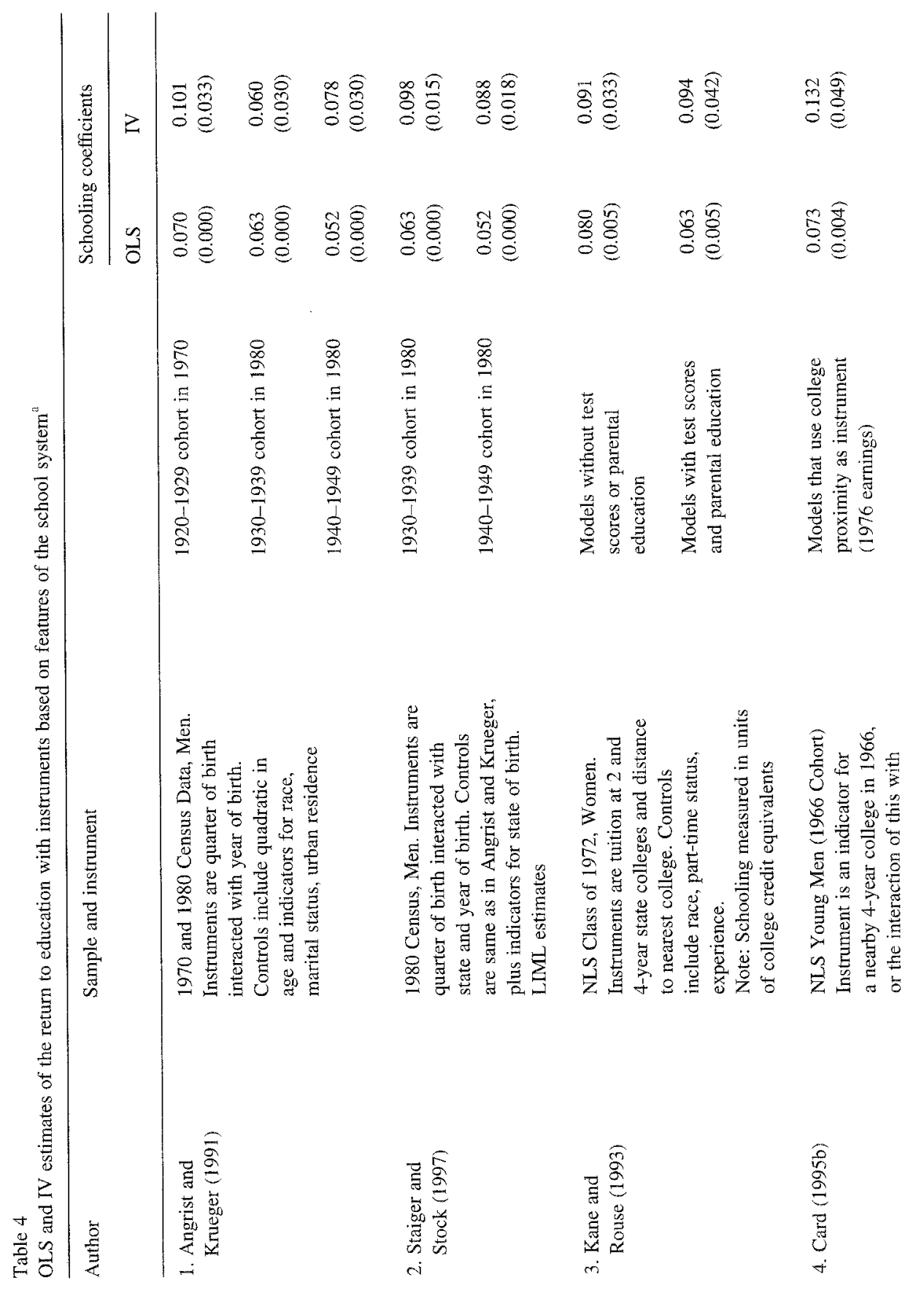




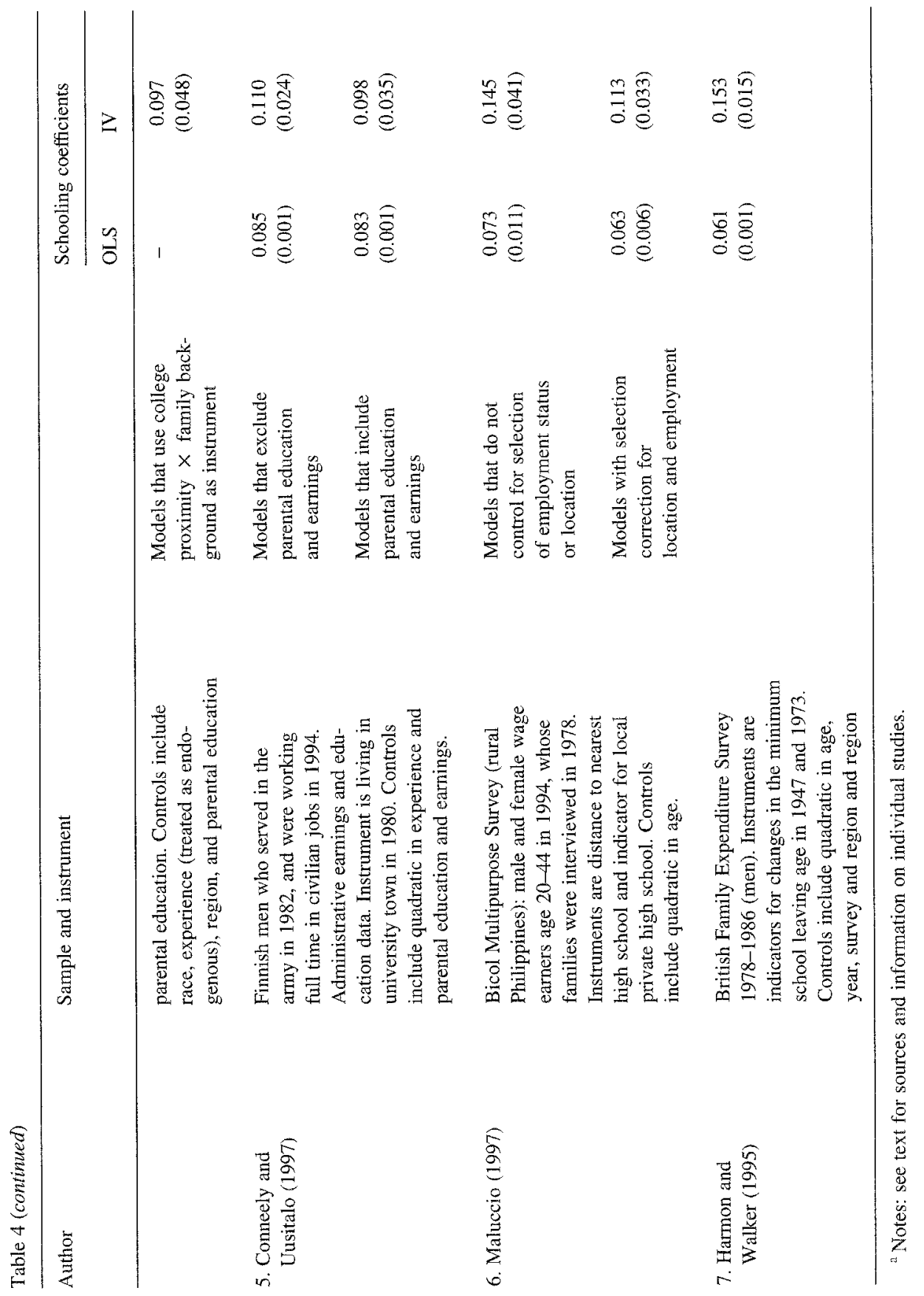


based on this idea. For each study I report both OLS and IV estimates derived from the same sample with the same control variables.

Angrist and Krueger's (1991) landmark study uses an individual's quarter of birth (interacted with year of birth or state of birth in some specifications) as an instrument for schooling. They show that men born from 1930 to 1959 with birth dates earlier in the year have slightly less schooling than men born later in the year - an effect they attribute to compulsory schooling laws. Angrist and Krueger note that people born in the same calendar year typically start school at the same time. As a result, individuals born earlier in the year reach the minimum school-leaving age at a lower grade than people born later in the year, allowing those who want to drop out as soon as legally possible to leave school with less education. Assuming that quarter of birth is independent of taste and ability factors, this phenomenon generates exogenous variation in education that can be used in an IV estimation scheme. It is worth emphasizing that compulsory schooling laws presumably raise the education of people who would otherwise choose low levels of schooling. If these individuals have higher or lower marginal returns to education than other people, a quarter-of-birth-based IV estimator may over- or under-estimate the average marginal return to education in the population as a whole.

Angrist and Krueger's empirical analysis confirms that the quarterly pattern in school attainment is paralleled by a similar pattern in earnings. As shown in Table 4, their IV estimates of the return to education are typically higher than the corresponding OLS estimates, although for some cohorts and specifications the two estimators are very close, and in no case is the difference between the IV and OLS estimators statistically significant.

Angrist and Krueger's findings have attracted much interest and some criticism. Bound et al. (1995) point out that several of Angrist and Krueger's IV models (specifically, those that use interactions between quarter of birth and state of birth as predictors for education) include large numbers of weak instruments, and are therefore asymptotically biased toward the corresponding OLS estimates. This "weak instruments" bias is less of an issue for the specifications reported in Table 4, which rely on a more parsimonious set of instruments. Moreover, to the extent that Angrist and Krueger's IV estimates are above the corresponding OLS estimates, one might infer that asymptotically unbiased estimates of the causal effect of education are even higher. This is confirmed by the findings of Staiger and Stock (1997), who re-analyze the 1980 Census samples used by Angrist and Krueger and compute a variety of asymptotically valid confidence intervals for standard IV and limited information maximum likelihood (LIML) estimates. Staiger and Stock's preferred LIML estimates, utilizing quarter of birth interacted with state of birth and year of birth as instruments, are reported in row 2 of Table 4 . These are somewhat above the corresponding conventional IV estimates and, 50-70\% higher than the OLS estimates.

A second criticism of Angrist and Krueger's findings, raised by Bound and Jaeger (1996), is that quarter of birth may be correlated with unobserved ability differences. Bound and Jaeger examine the schooling outcomes of earlier cohorts of men who were not subject to compulsory schooling institutions and find some evidence of seasonal 
patterns. They also discuss evidence from the sociobiology and psychobiology literature which suggests that season of birth is related to family background and the incidence of mental illness.

To evaluate the differences in family background by quarter of birth for cohorts roughly comparable to the ones in Angrist and Krueger's study, I compared the mean levels of parents' education by quarter of birth for children under 1 year of age in the 1940 Census. ${ }^{52}$ The mean years of education for mothers of children born in quarters I, II, III, and IV, are 9.04, 8.95, 8.97, and 8.95, respectively (with standard errors of about 0.05 ). The corresponding means of father's education are $8.61,8.50,8.52$, and 8.58 . These comparisons give no indication that children born in the first quarter come from relatively disadvantaged family backgrounds, and suggest that the seasonality patterns identified by Angrist and Krueger are probably not caused by differences in family background.

The third study summarized in Table 4, by Kane and Rouse (1993), is primarily concerned with the relative labor market valuation of credits from regular (4-year) and junior (2-year) colleges. Their findings suggest that credits awarded by the two types of colleges are interchangeable: in light of this conclusion they measure schooling in terms of total college credit equivalents. In analyzing the earnings effects of college credits, Kane and Rouse compare OLS specifications against IV models that use the distance to the nearest 2-year and 4-year colleges and state-specific tuition rates as instruments. Their IV estimates based on these instruments are $15-50 \%$ above the corresponding OLS specifications.

Two subsequent studies by Card (1995b) and Conneely and Uusitalo (1997) examine the schooling and earnings differentials associated with growing up near a college or university. The Card (1995b) study finds that when college proximity is used as an instrument for schooling in the National Longitudinal Survey (NLS) Young Men sample, the resulting IV estimator is substantially above the corresponding OLS estimator, although rather imprecise. Consistent with the idea that accessibility matters more for individuals on the margin of continuing their education, college proximity is found to have a bigger effect for children of less-educated parents. This suggests an alternative specification that uses interactions of college proximity with family background variables as instruments for schooling, and includes college proximity as a direct control variable. The IV estimate from this interacted specification is somewhat lower than the estimate using college proximity alone, but still about $30 \%$ above the OLS estimate.

The Conneely and Uusitalo (1997) study utilizes a very rich Finnish dataset that combines family background information, military test scores, and administrative earnings data for men who served in the army in 1982. Like Kane and Rouse (1993) and Card (1995b) they find that IV estimates of the returns to schooling based on college proximity exceed the corresponding OLS estimates by $20-30 \%$, depending on what other controls are added to the model. It is worth noting that all three of these studies report models that

\footnotetext{
${ }^{52}$ Quarter of birth is only reported in the 1940 Census for children under 1 year of age. There are 19,089 children under 1 year of age in the public use file, of whom $98.4 \%$ can be matched to a female head of household and $95.3 \%$ can be matched to a male head of househoid.
} 
control for a fairly detailed set of family background characteristics. Such controls are desirable if families that live near colleges have different family backgrounds, and if family background has some independent causal effect on earnings. Conneely and Uusi talo's IV estimate controlling for parental education and earnings is below the IV estimate that excludes these controls, but is still above the simplest OLS estimate without family background controls. Despite the rather large size of their sample (about 22,000 observations) and the very high quality of their underlying data, Conneely and Uusitalo's IV estimates are somewhat imprecise, and are not significantly different from their OLS estimates. $^{53}$

The sixth study in Table 4, by Maluccio (1997), applies the school proximity idea to data from the rural Philippines. Maluccio combines education and earnings information for a sample of young adults with data for their parents' households, including the distance to the nearest high school and an indicator for the presence of a local private high school. These variables have a relatively strong effect on completed education in this sample. Maluccio estimates OLS and conventional IV models using school proximity as an instrument, as well as IV models that include a selectivity correction for employment status and location. Both IV estimates are substantially above the corresponding OLS estimates. Maluccio's analysis suggests that the reliability of his schooling variable is somewhat lower than in conventional US or European datasets $\left(R_{0} \approx 0.8\right)$, accounting for some of the gap between the IV and OLS estimates. Unfortunately, Maluccio does not present OLS or IV models that control for family background. Rather, he presents IV models that use parental education and wealth as additional instruments for education, leading to slightly smaller but somewhat more precise IV estimates.

The final study summarized in Table 4, by Harmon and Walker (1995), examines the returns to education among a relatively large sample of British male household heads. Harmon and Walker use as instrumental variables for schooling a pair of dummy variables that index changes in the minimum school leaving age in Britain - from 14 to 15 in 1947 , and from 15 to 16 in 1973 . These are effectively cohort dummies that distinguish between men born before 1932, those born from 1933 to 1957, and those born after 1957. As shown in Table 4 their IV estimate is considerably above their OLS estimate ( 2.5 times higher) and is relatively precise. There are several aspects of their estimation strategy that suggest the need for caution in the interpretation of these findings, however. Most importantly, the 1947 law change - which is the major source of identification in their results - came just after World War II ${ }^{54}$ Moreover, Harmon and Walker do not allow for systematic growth in educational attainment for consecutive cohorts of men, other than that attributable to the law changes in 1947 and $1973 .{ }^{55}$ Both these factors may bias their IV estimator up.

\footnotetext{
5.3 Conneely and Uusitalo also implement a more general control function estimator, as described above.

${ }^{54}$ Ichino and Winter-Ebmer (1998) document that across Europe, the educational attainments of children born between 1930 and 1935 were substantially below those of children born just earlier or later.

${ }^{55}$ Their specifications control for age and survey year. One can infer the presence of important cohort effects from the fact that their survey year effects show a 0.5 year rise in educational attainment between surveys in 1979 and 1986, controlling for age and the school leaving age indicators.
} 
In addition to the studies included in Table 4, a number of other recent studies have used IV techniques to estimate the return to schooling. One innovative example is Hausman and Taylor (1981), which uses the means of three time-varying covariates (age and indicators for the incidence of bad health and unemployment) as instruments for education in a panel data model of earnings outcomes for prime-age men. Hausman and Taylor find that the return to schooling rises from about 0.07 in OLS specifications to $0.12-0.13$ in their IV specifications. Although more recent studies have not directly followed Hausman and Taylor's methodology, their use of mean age as an instrument for schooling is equivalent to using a linear cohort variable, and is thus similar in spirit to Harmon and Walker.

A very recent study by Ichino and Winter-Ebmer (1998) also utilizes birth cohort as a source of variation in schooling outcomes. In particular, Ichino and Winter-Ebmer focus on the earnings and schooling outcomes of Austrian and German men born from 1930 to 1935. They argue that World War II had a particularly strong effect on the educational attainment of children who reached their early teens during the war and lived in countries directly subject to hostilities. Using data for 14 countries they find relatively big differences in completed education for children in the 1930-1935 cohort in countries that were most heavily affected by the war (e.g., Germany, Austria and the UK) but relatively small differences for this cohort in other places (e.g., the US and Ireland). When they use an indicator for the 1930-1935 cohort as an instrument for low educational attainment they find that the earnings disadvantage roughly doubles from its OLS value. While one might be concerned that the 1930-1935 cohort suffered other disadvantages besides their disrupted education careers, these results are comparable to Harmon and Walker's (1995) in terms of the magnitude of the IV/OLS gap.

Another study not reported in Table 4, by Angrist and Krueger (1992), examines the potential effect of "draft avoidance" behavior on the education and earnings of men who were at risk of induction in the 1970-1973 Vietnam war draft lotteries. Since enrolled students could obtain draft exemptions, many observers have argued that the draft lottery led to higher college enrollment rates, particularly for men whose lottery numbers implied the highest risk of induction. If true, one could use draft lottery numbers - which were randomly assigned by day of birth - as instruments for education. While Angrist and Krueger (1992) report IV estimates based on this idea, subsequent research (Angrist and Krueger, 1995) showed that the link between lottery numbers and completed education is quite weak. In fact, the differences in education across groups of men with different lottery numbers are not statistically significant. Thus, the IV estimates are subject to the weak instruments critique of Bound et al. (1995), and are essentially uninformative about the causal effect of education. ${ }^{56}$

A conclusion that emerges from the results in Table 4 and from other IV-based studies is that instrumental variables estimates of the return to schooling typically exceed the corresponding OLS estimates - often by $30 \%$ or more. If one assumes on a priori grounds that

\footnotetext{
${ }^{56}$ The conventional IV estimates are typically equal to or just above the OLS estimates. Angrist and Krueger (1995) propose a "split sample" IV method to deal with the weak instruments problem. The split-sample IV estimates are all very imprecise.
} 
OLS methods lead to upward-biased estimates of the true return to education, the even larger IV estimates obtained in many recent studies present something of a puzzle. A number of hypotheses have been offered to explain this puzzle. The first - suggested by Bound and Jaeger (1996), for example - is that the IV estimates are even further upward biased than the corresponding OLS estimates by unobserved differences between the characteristics of the treatment and comparison groups implicit in the IV scheme. This is certainly a plausible explanation for some part of the gap between OLS and IV in studies that do not control directly for family background, but it is less compelling for studies that include family background controls.

A second explanation - proposed by Griliches (1977) and echoed by Angrist and Krueger (1991) - is that ability biases in the OLS estimates of the return to schooling are relatively small, and that the gaps between the IV and OLS estimates in Table 4 reflect the downward bias in the OLS estimates attributable to measurement errors. The imprecision of most of the IV estimates in Table 4 makes it difficult to rule out this explanation on a study-by-study basis. Since measurement error bias by itself can only explain a $10 \%$ gap between OLS and IV, however, it seems unlikely that so many studies would find large positive gaps between their IV and OLS estimates simply because of measurement error. ${ }^{57}$

A third possibility, suggested in a recent overview of the returns to education literature by Ashenfelter and Harmon (1998), is "publication bias". They hypothesize that in searching across alternative specifications for a statistically significant IV estimate, a researcher is more likely to select a specification that yields a large point estimate of the return to education. As evidence of this behavior they point to a positive correlation across studies between the IV-OLS gap in the estimated return to education and the sampling error of the IV estimate. ${ }^{58}$

While all three of these explanations have some appeal, I believe a fourth explanation based on underlying heterogeneity in the returns to education is also potentially important. Factors like compulsory schooling or the accessibility of schools are most likely to affect the schooling choices of individuals who would otherwise have relatively low schooling. If these individuals have higher-than-average marginal returns to schooling, then instrumental variables estimators based on compulsory schooling or school proximity might be expected to yield estimated returns to schooling above the corresponding OLS estimates. A necessary condition for this phenomenon is that marginal rates of return to schooling are negatively correlated with the level of schooling across the population. In the model presented in Section 3, the covariance of the return to schooling with the level of schooling is $\mathrm{E}\left[\beta_{i}\left(S_{i}-\bar{S}\right)\right]=\left(k f-k_{1}\right) \operatorname{Var}\left[S_{i}\right]$, where $k=k_{1}+k_{2}$ and $f$ is the fraction of the variance of schooling outcomes attributable to variation in ability. If individual discount rates are constant (i.e., $k_{2}=0$ ) this covariance is necessarily negative. Even if individuals have

\footnotetext{
${ }^{57}$ One caveat to this conclusion is the possibility that measurement errors are larger, or more systematically correlated with schooling levels, for individuals most affected by the interventions underlying the analyses in Table 4. Kane et al. (1997) find some evidence of this.

${ }^{58}$ Across the studies in Table 4 the IV-OLS gap is negatively related to the sampling error of the IV estimate, although the correlation is positive if the Harmon-Walker study is excluded.
} 
increasing marginal discount rates (because of taste factors or financial constraints) marginal returns to education will be higher for less-educated individuals if ability differences are not "too important" in the determination of schooling outcomes, and if the marginal return to schooling is decreasing. In this case, IV estimates of the return to schooling based on institutional changes that raise schooling levels among less-educated subgroups may well exceed the corresponding OLS estimates.

\subsection{Estimators using family background as a control or instrument}

Table 5 summarizes some findings on the use of family background (typically parental education or the education of a sibling) as either a control variable or instrument in models of the return to education. For most of the studies presented in the table, I report three estimates of the return to education: an OLS estimate that excludes family background controls; an OLS estimate that controls for one or more family background characteristics; and an IV estimator that uses the same family background variable(s) as an instrument for education. For two of the studies (Miller et al., 1995; Ashenfelter and Rouse, 1998) I also present measurement-error corrected IV estimates for models that include both an individual's education and his or her sibling's education, using multiple reports of the siblings' education as instruments. ${ }^{59}$ It should be noted that most of the studies described in Table 5 do not focus directly on the specifications I have summarized, but rather report these results incidentally.

The first group of studies in the table utilize parental education as a family background indicator. The Card (1995b) and Conneely and Uusitalo (1997) studies have already been described. ${ }^{60}$ I prepared the estimates for the General Social Survey (GSS) sample specifically for this review. ${ }^{61}$ The Ashenfelter and Zimmerman (1997) paper uses father's education as a background variable in one set of models, and brother's education in another. With the exception of the results for women in the GSS, the results for these four studies are remarkably consistent. In all four cases the addition of parental education as a control variable (or set of controls) lowers the measured return to education by $5-10 \%$ (about the magnitude of the decline expected on account of measurement error factors alone); while the use of parental education as an instrument leads to IV estimates that are at least $15 \%$ above the corresponding OLS estimates. Moreover (although not shown in the table), the coefficient of the parental education variable itself is positive and significant, but small in magnitude. For women in the GSS sample the addition of mother's education has essentially no effect on the return to a woman's own education, and higher mother's

\footnotetext{
${ }^{5 y}$ Specifically, following the lead of Ashenfelter and Krueger (1994), both Miller et al. and Ashenfelter and Rouse make use of information collected from twins on their own and their sibling's education.

${ }^{60}$ The IV estimate associated with the data in my $1995 \mathrm{~b}$ study is not reported in the published version of the paper.

${ }^{61}$ The GSS has the advantage of including large samples of men and women. Earnings information in this survey pertains to annual income: I imputed interval midpoints to the categorical data in the survey.
} 
Table 5

Estimates of the return to education with and without controlling for family background, and IV estimates using family background ${ }^{\mathrm{x}}$

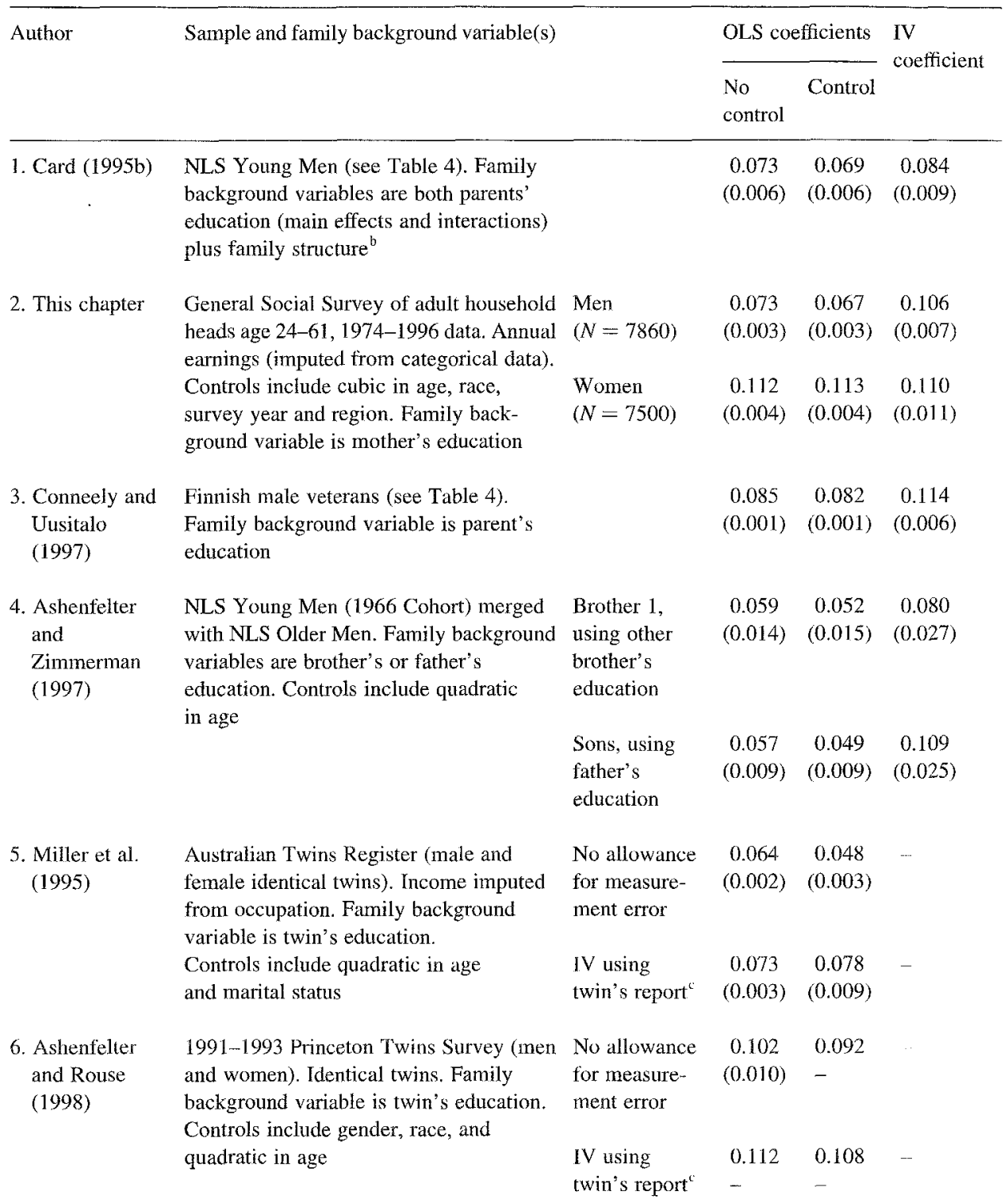


Table 5 (continued)

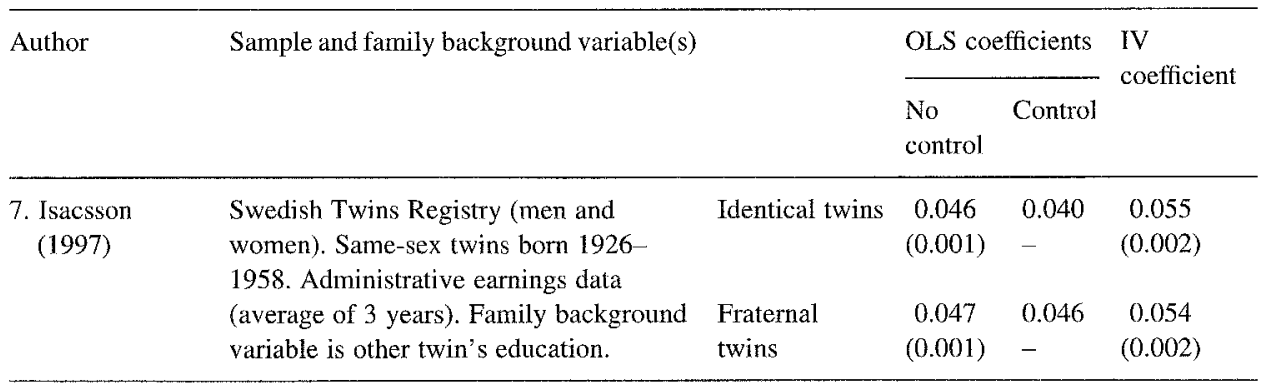

\footnotetext{
" Notes: See text for sources and information on individual studies.

${ }^{\mathrm{b}}$ In this study the IV specification treats education and experience as endogenous and uses family background variables and age as instruments.

${ }^{\mathrm{c}}$ In these specifications each twin's education is instrumented by the other twin's report of their education.
}

education has a very small negative effect on earnings. As a consequence the IV estimate for the GSS female sample is slightly lower than the OLS estimate. ${ }^{62}$

The fifth, sixth and seventh studies described in Table 5 all utilize samples of twins: in each case family background is measured by a sibling's education. Interestingly, the effect of adding a twin's education in these samples is similar to the effect of adding parental background in the other studies: the coefficient of own-schooling falls by $10-25 \%$. Since twin's education levels are even more highly correlated than father-son or sibling education levels, the magnitude of this drop is not far off the decline attributable to measurement error factors alone. The Miller et al. and Ashenfelter-Rouse studies allow a direct test of the "pure measurement error" explanation, since in both cases the authors report estimates for IV models that include both twins' education levels (as reported by one twin) instrumented by the education levels reported by the other twin. ${ }^{63}$ As shown in the table, the measurement-error corrected estimates of the return to own-education with controls for twin's-education are about equal to the corresponding measurement error-corrected OLS estimates that do not control for family background.

Based on these findings for twins, and the results in the other studies in Table 5, I conclude that whatever biases exist in conventional OLS estimates of the return to education are also present in models that control for family background. Apart from an effect attributable to measurement error, the return to education is about the same when controls are introduced for the education of one's parents or siblings. In the context of the models summarized in Table 3, this finding suggests that the bias component in the simple OLS

\footnotetext{
${ }^{62}$ Recall that these three estimators are mechanically linked. If mother's education has a negative effect controlling for daughter's education, then the IV estimate using mother's education as an instrument is necessarily below the OLS estimate.

${ }^{63}$ Ashenfelter and Rouse (1998) actually report estimates of models that include $S_{i 1}$ and $\left(S_{i 1}+S_{i 2}\right) / 2$ (i.e., average family education). These coefficients can be "unscrambled" to show the direct effects of $S_{i 1}$ and $S_{i 2}$, although there is not enough information to construct standard errors for these effects.
} 
estimator, $\lambda_{0}+\psi_{0} \bar{S}$, is about the same size as, or only slightly bigger than, the bias in the estimator that controls for family background, $\lambda_{1}+\psi_{1} \bar{S}$.

On the other hand, measures of family background such as parental or sibling education typically exert a small positive effect on earnings (i.e., the term $\lambda_{2}+\psi_{2} \bar{S}$ is positive). Thus, IV estimates using family background as an exogenous determinant of schooling are often (but not always) substantially above the corresponding OLS estimates. ${ }^{64}$ This conclusion is potentially important for interpreting other IV estimates of the return to education based on factors like proximity to college or other institutional features of the education system. To the extent that individuals in the treatment and control groups of a quasi-experimental analysis have different family backgrounds, one might expect a positive upward bias in the resulting IV estimators. The IV results in Table 5 suggest that it is particularly important to control for family background (or verify that family background is the same in the treatment and control groups) in any instrumental variables analysis of the return to schooling.

As noted in Section 3, although the addition of controls for family background will not necessarily lead to consistent estimates of the true return to schooling, under certain assumptions estimates from models that control for family background can be used to obtain consistent estimates of the average marginal return to education. Specifically, if one assumes that $\lambda_{1}+\psi_{1} \bar{S}=\lambda_{2}+\psi_{2} \bar{S}$, the upward bias in the estimated own schooling coefficient is equal to the probability limit of the family background variable's coefficient. Thus one can subtract the latter from the former and obtain a consistent estimate of $\bar{\beta}$. Given that family background variables like the education of a parent or sibling typically exert a small positive effect on earnings, application of this procedure to the studies in Table 5 would lead to estimates of the average marginal return to schooling that are somewhat below the OLS estimates. Subtraction of the coefficient of a parent's or sibling's education from the own schooling coefficient is equivalent to a within-family estimator. Since the assumptions required to justify this estimator are most appealing in the case of twins, I defer a more detailed discussion to the next section.

Under slightly weaker assumptions but with more information - specifically, with information on the earnings of the family member whose data is used as a control - it still may be possible to estimate the average marginal return to schooling. In particular, under the "pure family effects" assumption that siblings or parents share the same abilities, one can derive an estimate of $\bar{\beta}$ from the coefficients of a seemingly unrelated regression of each family members' earnings on his or her own schooling, and the other

\footnotetext{
${ }^{64}$ This conclusion differs slightly from Griliches' (1979, p. S59) tentative conclusion that "measured parental characteristics... appear to affect earnings primarily via their effect on the level of achieved schooling. The market does not appear to pay for them directly." Another dimension of family background that seems to have some effect on education of women is the sex composition of one's siblings. Butcher and Case (1994) show that women with brothers (rather than sisters) have slightly more education. They also use sex composition as an instrument for schooling and find much larger IV than OLS estimates of the return to schooling. Even though sex composition is random, it is unclear that its only effect on earnings is via education: thus Butcher and Case's (1994) IV estimates may be biased.
} 
family members schooling (see Eqs. (17a) and (17b)). Ashenfelter and Zimmerman report estimates from this procedure applied to brothers and father-son pairs, with and without corrections for measurement error biases. Their estimation methods ignore heterogeneity in the returns to schooling. This is not a problem for their sample of brothers, who have roughly the same mean education, but may be more of an issue for their father-son sample, since the sons have about four years more education than the fathers. ${ }^{65}$

After accounting for plausible measurement error biases, Ashenfelter and Zimmerman's findings for brothers imply estimates of $\bar{\beta}$ about equal to the corresponding OLS estimates. Their estimates for father-son pairs are more sensitive to assumptions about whether the true return to education is the same for fathers and sons, and whether fathers and sons are exchangeable in the projection equations for the latent family ability term. Their least restrictive specifications suggest a slightly lower estimate of $\bar{\beta}$ for fathers than the corresponding OLS estimate, but a much lower estimate of $\bar{\beta}$ for sons. Given their results for brothers, however, an alternative interpretation is that the "pure family effects" assumption is inappropriate for father-son pairs. In fact, Ashenfelter and Zimmerman find that a slightly modified model that allows latent family ability to have a differential effect on the intercepts of fathers' and sons' earnings equations seems to fit the data fairly well. After correcting for measurement error, this specification implies estimates of $\bar{\beta}$ for fathers and sons that are $25-50 \%$ lower than the corresponding OLS estimates.

\subsection{Studies of education and earnings using twins}

Table 6 summarizes five recent studies that compare the education and earnings of twins. Two features of these studies contrast with the earlier literature on twins surveyed by Griliches (1979). First, the samples in the recent literature are relatively large, and tend to include a broader range of age and family background groups. Second, following the lead of Ashenfelter and Krueger's (1994) innovative paper, most of the recent studies squarely address the problem of measurement error. For each study I report a cross-sectional (OLS) return to education, and two within-family differenced estimates: one estimated by OLS and the other corrected for measurement error.

The Ashenfelter and Rouse (1998) study utilizes 3 years of data collected in the Princeton Twins Survey (PTS): their sample includes 340 pairs of identical twins, $60 \%$ of whom are women. As shown for the two specifications in Table 6, Ashenfelter and Rouse's within-family estimates of the return to education are about $30 \%$ lower than their corresponding OLS estimates. This finding contrasts with the results in Ashenfelter and Krueger (1994) based on only 1 year of data from the PTS, which indicated a bigger within-family than OLS estimate. ${ }^{66}$ The PTS questionnaire asked each twin their own education and their sibling's education. This extra set of responses allow Ashenfelter and

\footnotetext{
${ }^{65}$ If there is heterogeneity in returns to education Eqs. (17a) and (17b) imply that the coefficients of the seemingly unrelated regression depend on the mean levels of education of the different family members.

${ }^{60}$ Rouse (1997, Table 3) presents some results which suggest that Ashenfelter and Krueger's findings are attributable to sampling variability associated with their relatively small sample.
} 
Rouse to use one twin's responses about the difference in schooling for the pair as an instrument for the other twin's responses. ${ }^{67}$ The IV estimates, presented in the third column of Table 6 , are $25 \%$ larger than the simple differenced estimates, and about $10 \%$ below the corresponding OLS estimates. Rouse (1997) extends the analysis in Ashenfelter and Rouse with one further year of data from the PTS. Her findings, summarized in row 2 of Table 6, are generally consistent with those in Ashenfelter and Rouse (1998), although Rouse's IV estimate is somewhat above the estimate reported by Ashenfelter and Rouse, and actually exceeds the OLS estimate for the same sample. ${ }^{68}$

The study by Miller et al. (1995) uses data for 1170 Australian twin pairs (about onehalf female). The advantage of the large sample size is offset by the absence of useable income data: Miller et al. have to impute incomes based on two-digit occupation. Thus, twins with the same two-digit occupation are coded as having the same income. ${ }^{69}$ For identical twins Miller et al. (1995) find that the within-family estimate of the return to education is almost $50 \%$ lower than the cross-sectional estimate; for fraternal twins, the within-family estimator is $40 \%$ lower. Like the PTS, the Australian twins dataset includes multiple reports of each twin's education. Miller et al. (1995) follow Ashenfelter and Krueger's (1994) procedure of using one twin's responses on the difference in schooling for the pair as an instrument for the other's responses. For identical twins, the resulting IV estimate is about $40 \%$ above the differenced OLS estimate, but still $25 \%$ below the crosssectional estimate. For fraternal twins the IV estimate is actually slightly above the OLS estimate.

Behrman et al. (1994) analyze a dataset that pools the NAS-NRC sample of white male World War II veterans with data on men from the Minnesota Twins Registry. ${ }^{70}$ While the main focus of their paper is on models of inter-familial resource allocation, an appendix table reports cross-sectional and within-family estimates of the return to schooling. For identical twins, Behrman et al. (1994) find that the within-family estimate of the return to schooling is about $50 \%$ as large as the cross-sectional OLS estimate, ${ }^{71}$ while for fraternal

\footnotetext{
${ }^{67}$ With two measures of each twin's education there are four possible estimates of the differences in education. Ashenfelter and Krueger (1994) and Rouse (1997) examine the covariance structure of these differences and conclude that the measurement errors in a given twin's reports of her own education and her sibling's education are slightly correlated. Differences in the reports that a given twin provides of the two education levels will eliminate this correlation.

${ }^{68}$ The IV estimate for Rouse (1997) in Table 6 (which uses one twin's report of the difference in the pair's education as an instrument for the other twin's) is not reported in her paper, but was reported by Rouse in a private communication to Gary Solon.

${ }^{69}$ It would be interesting to compare the use of actual income data and imputed incomes in a dataset that includes both, such as the PTS, to judge whether the imputation differentially affects cross-sectional versus within-family estimates of the return to education.

${ }^{70}$ The NAS-NRC sample has been extensively analyzed by some of the same co-authors, e.g., Behrman et al. (1980). Behrman et al. impute earnings for the Minnesota sample using occupation.

${ }^{71}$ This ratio is slightly higher than the ratio reported in earlier work by Behrman et al. (1980) for identical twins in the NAS-NRC sample. Griliches (1979) characterized their results as showing a $65 \%$ reduction in the return to schooling between the OLS and within-family estimators.
} 
twins the relative ratio is $80 \%$. Although they do not actually estimate IV models to correct for measurement error, Behrman et al. (1994) report that the reliability of the withinfamily difference in schooling for identical twins in the NAS-NRC sample is 0.62 . Using this estimate, a corrected estimate of the within-family return to schooling for identical twins is 0.056 . Behrman et al. (1994) do not give a comparable estimate of the reliability ratio for fraternal twins. Results in Miller et al. (1995) and Ashenfelter and Krueger (1994), however, suggest that the reliability of within-family differences in schooling for fraternal twins is about 0.8 . Using this estimate, a corrected estimate of the withinfamily return to schooling for fraternal twins is 0.071 . The relative magnitudes of the OLS and within-family estimators for identical and fraternal twins in Behrman et al. (1994) and Miller et al. (1995) are therefore very comparable.

Finally, Isacsson (1997) analyses earnings and schooling differences among a large sample of Swedish twins (about one-half women). For a subsample of the data he has information on two measures of schooling: one in a register held by Statistics Sweden; another based on self-reported education qualifications. ${ }^{72}$ As shown in Table 6, Isacsson finds that the within-family estimate of the return to schooling for identical twins in the subsample with two schooling measures is less than $50 \%$ as large as the corresponding OLS estimator, while for fraternal twins the ratio is $80 \%$. He constructs IV estimates for the within-family model using the difference in the survey measures of schooling as an instrument for the differences in the registry measures. ${ }^{73}$ For identical twins, the withinfamily IV estimator is only marginally above the within-family OLS estimate, implying almost no measurement error bias. For fraternal twins, on the other hand, the IV procedure raises the within-family estimate by $35 \%$. Since one would have expected a bigger measurement error attenuation for identical twins than fraternal twins, the patterns of Isacsson's findings are somewhat puzzling.

Isacsson (1997) also constructs measurement-error-corrected estimates of the return to education for a broader sample of twins, assuming "low" and "high" estimates of the reliability of his main schooling measure (reliabilities of 0.85 and 0.95 , respectively). The results are summarized in the last two rows of Table 6 . For fraternal twins the corrected within-family estimates lie in a fairly tight range $(0.044-0.060)$ that brackets the withinfamily IV estimate based on the two schooling measures $(0.054)$. For identical twins the range of the corrected estimates is wider $(0.027-0.060)$ and lies above the within-family IV estimate based on the two schooling measures (0.024).

Taken as a whole, Isacsson's results suggest that the measurement-error-corrected within-family estimate of the return to education for fraternal twins in Sweden is about as big or even bigger than the corresponding OLS estimate. The precise relative magnitude of the measurement-error-corrected within-family estimate for identical twins is more

\footnotetext{
${ }^{72}$ There is a substantial difference in timing in the two measures. The register-based estimate pertains to 1990 while the self-reported measures were collected in 1974. Isacsson's earnings data are based on administrative records for 1987, 1990, and 1993.

${ }^{73} \mathrm{He}$ also reports some evidence on the appropriateness of the assumptions that are needed to justify consistency of these estimates.
} 


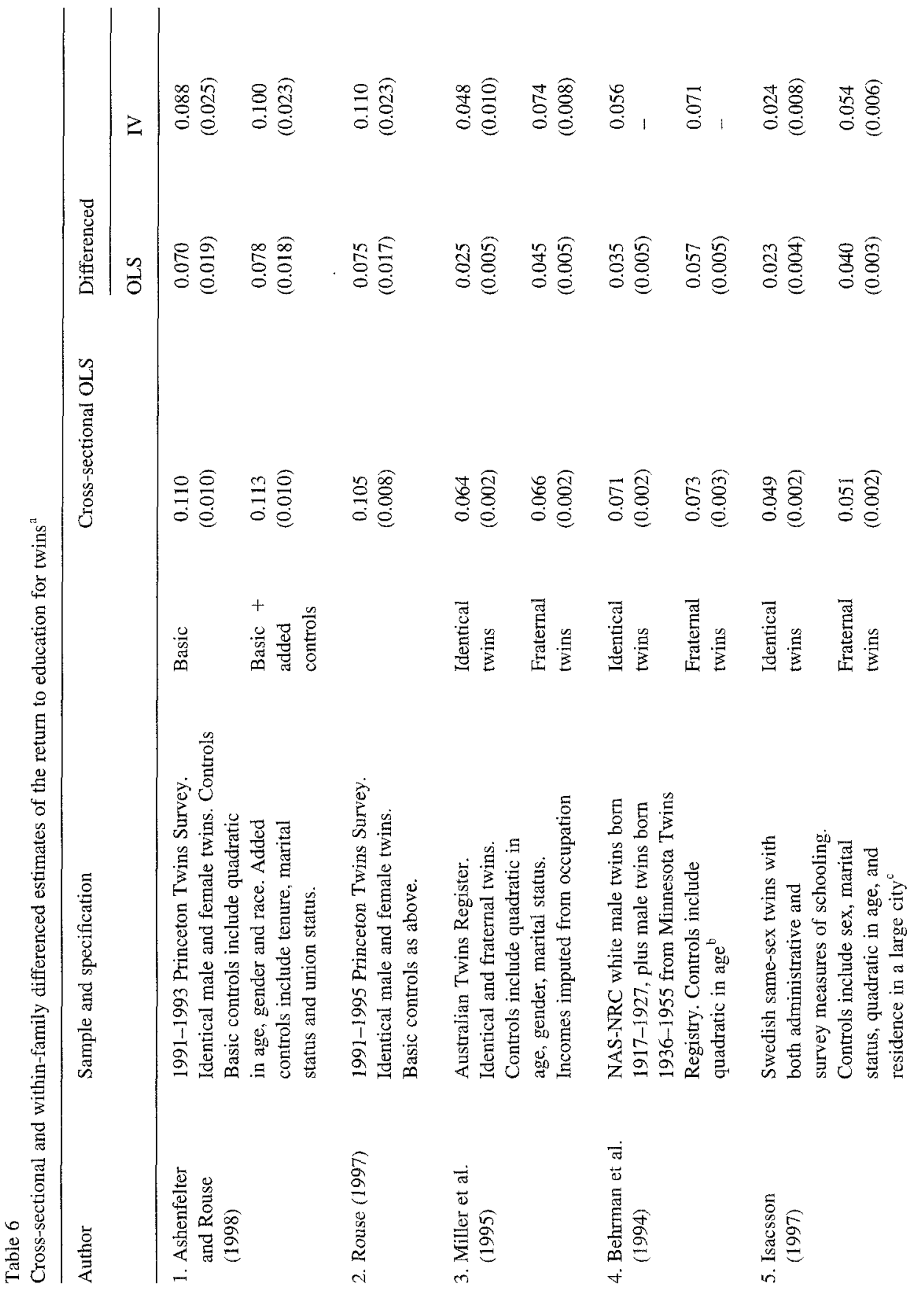




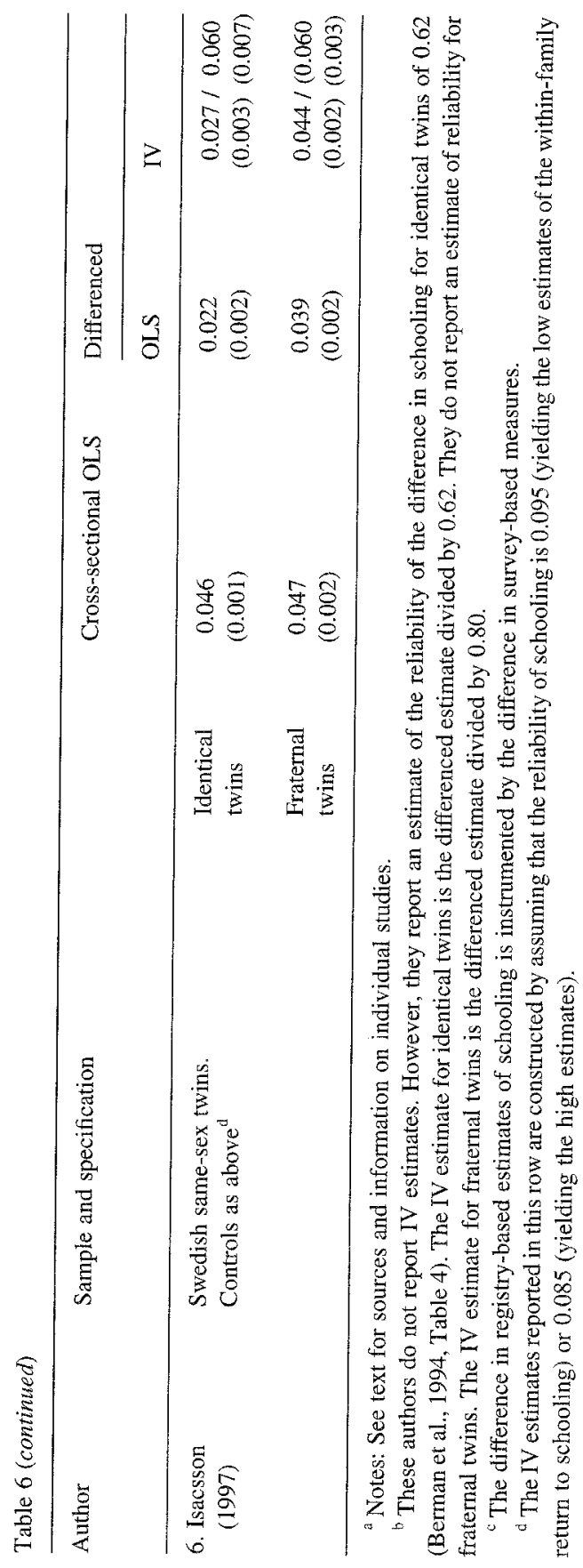


uncertain, and seems to be very sensitive to assumptions about measurement error. A cautious interpretation of Isacsson's findings is that there may be some upward bias in OLS estimates of the return to schooling relative to the within-family estimate for identical twins.

What general conclusions can be drawn from the recent twins literature? Suppose on a priori grounds one believes that identical twins have identical abilities. Then the withinfamily estimator for identical twins, corrected for measurement error biases, is consistent for the average marginal return to schooling in the overall twins population. ${ }^{74}$ Assuming that this is the case, the estimates in Table 6 suggest that a cross-sectional OLS estimator yields a slightly upward-biased estimate of the average marginal return to education: the magnitude of the bias ranges across studies from 50\% (Isacsson) to zero (Rouse, 1997). Given the limitations of the imputed earnings data used by Miller et al. (1995) and Behr-man et al. (1994), and the uncertainties in the measurement error corrections for Isacsson's study, I put more weight on the Ashenfelter-Rouse and Rouse studies, which suggest a smaller range of biases - more like $10-15 \%$.

A second conclusion emerges from the three studies that present results for fraternal twins. In these studies the measurement-error-corrected within-family estimator of the return to education for fraternal twins is about equal to the corresponding OLS estimator. Interestingly, Ashenfelter and Zimmerman's measurement-error-corrected estimate of the return to schooling for brothers - constructed under the assumption that brothers have identical abilities - is also about equal to the corresponding OLS estimate. Since fraternal twins are essentially brothers (or sisters) with the same age, the similarity of the findings for fraternal twins and brothers is reassuring. Assuming that OLS estimates are upwardbiased relative to the true average causal effect of education, the within-family estimates based on fraternal twins or brothers must also be upward-biased. Moreover, since the OLS estimator is downward biased by measurement error, whereas the corrected within-family estimates for fraternal twins or brothers are not, one can conclude that the ability bias in within-family estimators for fraternal twins or brothers are smaller than the ability bias in cross-sectional OLS estimators: on the order of one-half as large. ${ }^{75}$ This implies that ability differences between brothers or sisters are relatively less important determinants of within-family schooling outcomes than are overall ability differences in the determination of schooling outcomes for the population as a whole.

Such a finding opens up the interesting question of how and why families affect the schooling decisions of children with differential abilities. Behrman et al. (1982) present a model incorporating parental preferences in the distribution of education resources across siblings that is consistent with either reinforcing or compensatory behavior (i.e., families may spend more educating either their more- or less-able children). Their empirical findings support the notion of compensatory parental behavior - behavior that would lead to a

\footnotetext{
${ }^{74}$ The "twins population" may be fairy broad or very narrow, depending on the dataset.

${ }^{75}$ Write the plim of the OLS estimator as $R_{0}\left(\bar{\beta}+G_{\text {ols }}\right)$ and the plim of the measurement-error corrected fraternal-twins-based estimator as $\left(\bar{\beta}+G_{f}\right)$. If the OLS and corrected fraternal twins estimators are about equal, then $R_{0}\left(\bar{\beta}+G_{\text {ols }}\right)=\left(\bar{\beta}+G_{f}\right)$. Assuming that $R_{0} \approx 0.9$, if $G_{f}$ is $10-20 \%$ of $\bar{\beta}, G_{f} / G_{\text {ols }}$ is $45-60 \%$.
} 
reduction in the relative importance of ability differences in determining education outcomes within families than between families. ${ }^{76}$

If one does not believe that identical twins have identical abilities, then even the withinfamily estimator of the return to education for identical twins may be biased by ability differences. Ashenfelter and Rouse (1998) present a variety of indirect evidence in support of the hypothesis that identical twins are truly identical, and that differences in their schooling levels are attributable to random factors rather than to ability differences. For example, they report that schooling differences among identical twins are uncorrelated with birth order and with their spouse's education. ${ }^{77}$ Despite this evidence, and the strong intuitive appeal of the "equal abilities" assumption for identical twins, however, I suspect that observers with a strong a priori belief in the importance of ability bias will remain unconvinced.

\subsection{Direct evidence on the heterogeneity in returns to education}

A final set of results in the recent literature that are worth briefly reviewing concern observable sources of variation in the return to education. Among the potential sources of heterogeneity that have been identified and studied are school quality, family background, and ability, as measured by IQ or aptitude test scores.

Much interest in the connection between school quality and the return to education was stimulated by the observation that black men had substantially lower returns to schooling than white men in the early 1960s (e.g., Welch, 1973). Moreover, most of the convergence in black-white relative wages that occurred in the 1960s and 1970s can be attributed to a combination of rising relative returns to education for more recent cohorts of black men, and the increasing relative education of blacks relative to whites (Smith and Welch, 1986; 1989). Since the relative quality of schools attended by black students in the segregated southern states improved significantly between 1920 and 1960 (Card and Krueger, 1992b), these facts have led researchers to speculate that increases in school quality may lead to increasing educational attainment and higher returns to education.

Card and Krueger (1992a,b) estimate rates of return to schooling for different cohorts of white and black men who were born in different states and correlate these returns with measures of school quality by cohort and state-of-birth. ${ }^{78}$ A distinctive feature of measured returns to education which complicates this analysis is the fact that education-related wage differentials are higher in some parts of the US than others. ${ }^{79}$ Card and Krueger address

\footnotetext{
${ }^{76}$ The more recent study by Behrman et al. (1994), however, finds reinforcing behavior in the allocation of school resources within families.

${ }^{77}$ The latter finding seems to be at odds with results in Behrman et al. (1994, Table A2) who report a strong relationship between differences in education and differences in spouses' education among identical twins.

${ }^{78}$ Previous studies that model school quality effects on the return to education include Akin and Garfinkel (1980) and Link et al. (1980).

${ }^{79}$ This feature of the US labor market was documented in Chiswick (1974). Dahl (1997) presents a thorough summary of the variation in returns to edncation by state in 1980 and 1990, and evaluates the contribution of selective migration to these patterns.
} 
this by assuming an additive structure to the return to education: an individual born in one state and working in another receives the sum of a state-of-birth component (that presumably varies with school quality); and a state-of-residence component. ${ }^{80}$ Under this assumption, Card and Krueger (1992a,b) show that the state-of-birth components in the returns to schooling are systematically correlated with characteristics of the school system. For example, their results suggest that lowering the state-wide pupil-teacher ratio by 10 students raises the rate of return to education earned by students from the state by about 0.9 percentage points.

From the point of view of the models presented in Section 3, another interesting finding reported by Card and Krueger is that students who grew up in states with better quality schools acquired more education. For example, their results for white men imply that a reduction in the statewide pupil-teacher ratio by 10 students raises average educational attainment by 0.6 years. In principle, school quality may affect educational attainment by lowering the marginal cost of schooling, or by raising the marginal benefits of schooling, or both. If one ignores the cost effect, then the implied estimate of the parameter $\mathrm{k}$ in $\mathrm{Eq}$. (4) for white men born in the 1920-1950 period is $0.013{ }^{81}$ This in turn suggests that the magnitude of the endogeneity component $\left(\psi_{0} \bar{S}=k f \bar{S}\right)$ in the OLS estimate of the return to schooling is about $0.15 f$, where $f$ is the fraction of the variance in school outcomes that is attributable to differences in ability versus differences in tastes. Assuming that the endogeneity bias is about 0.015 (as implied by the results in Ashenfelter and Rouse, 1998) $f$ ' is about $10 \%$. These calculations are obviously speculative: nevertheless, they illustrate the potential usefulness of data on observable determinants of the return to education in developing a better understanding about the causal effects of education.

Further evidence on the extent of heterogeneity in returns to education and its relationship to school quality and family background is presented in a series of papers by Altonji and Dunn $(1995,1996 \mathrm{a}, \mathrm{b})$ that study earnings and schooling data for sibling pairs in the National Longitudinal Surveys of Young Men and Young Women and the Panel Study of Income Dynamics. Altonji and Dunn fit models of log earnings that include education, various control variables, and interactions of education with parental education, IQ, and school quality characteristics. ${ }^{82}$ They estimate these models excluding and including family fixed effects. The latter specifications are perhaps the most interesting aspect of their work, since in these models the direct or main effects of family background are held

\footnotetext{
${ }^{80}$ This assumption is criticized by Heckman et al. (1996) because it ignores the possibility of selective migration. Interestingly, Heckman et al. find larger average effects of school quality in models that control for selective migration by including a function of the distance that individuals have migrated between their state of residence and state of birth. See Card and Krueger (1996) for a summary and discussion.

${ }^{81}$ In the model, $S_{i}=\left(b_{i}-r_{i}\right) / k$. If a rise in school quality that raises the average return to schooling by 0.009 leads to 0.6 years of added schooling then $k \approx 0.013$.

${ }^{82}$ There is an earlier literature that includes interactions of family background and ability measures with schooling. Hauser (1973) found little evidence that father's occupational status affected the return to schooling of sons. Similarly, Olneck (1979) concludes that IQ and father's education have little systematic effect on the return to education. On the other hand, Hause (1972) and Willis and Rosen (1979) find positive interactions between aptitude test scores and education.
} 
constant. As one would expect from the discussion of sibling and twin models in Section 3 , measurement error plays a potentially important role in the within-family models: Altonji and Dunn develop estimates of the likely magnitude of the attenuation biases that arise in these models and interpret their estimates accordingly.

Altonji and Dunn's results suggest that higher school quality, as measured by spending per pupil, average teacher salaries, or a composite index, raises the return to education. With respect to family background and ability their results are less conclusive. In some of their models that include family fixed effects they find that higher mother's education raises the return to education, although in other samples and specifications the effects are weak and even opposite-signed. Like the earlier literature, they find small and unsystematic effects of parental education on the returns to education in models that exclude family fixed effects. The effects of IQ on the return to education are generally positive (but imprecisely estimated) in the within-family models but negative in the models that exclude family effects.

Ashenfelter and Rouse (1998) also analyze the effects of family background on the returns to schooling for identical twins. Consistent with Altonji and Dunn, their estimates of the interactions between parental education and the difference in schooling between identical twins are positive but imprecise.

Finally, Ashenfelter and Rouse (1998) present some interesting evidence on the existence of declining marginal returns to schooling (i.e., concavity in the relationship between $\log$ earnings and schooling at the individual level). They augment a simple within-family differenced earnings equation for identical twins with an interaction between the twins' average education and their difference in education. In the context of the model represented by Eq. (15) the coefficient on this interaction is an estimate of the coefficient $k_{1}{ }^{83}$ Ashenfelter and Rouse find that returns to schooling decline with the average level of schooling - from about 0.12 at 9 years of schooling to 0.08 at 16 years of schooling - although the gradient is not precisely measured. Such direct evidence of a declining marginal return to schooling supports the interpretation of the IV estimators in Table 4 as yielding estimates of the marginal return to schooling for people who would otherwise have below-average schooling outcomes (relative to the population analyzed in each study).

This brief review suggests three main conclusions. First, the return to education is related to some observable covariates, such as race, school quality, family background measures, and perhaps measured ability. Second, factors such as race, school quality, and mother's education that are associated with higher returns to education are also generally associated with higher levels of education. These patterns are compatible with an optimizing model of school quality in which individuals are more likely to choose higher levels of education if the return to education is higher. Third, but more tentatively, individual returns to education are declining with the level of education.

\footnotetext{
${ }^{83}$ Assuming equal abilities for identical twins, Eq. (15) implies that $\Delta \log y_{i}=b_{i} \Delta S_{i} \cdots 1 / 2 k_{1}\left(S_{i 1}^{2}-S_{i 2}^{2}\right)$ $\approx b_{i} \Delta S_{i}-k_{1} \bar{S}_{i} \Delta S_{i}$, where $\bar{S}_{i}$ is the average education of the twins in family $i$.
} 


\section{Conclusions}

Taken as a whole, I believe that the recent literature on the returns to education points to five key conclusions:

1. Consistent with the summary of the literature from the 1960 s and 1970 s by Griliches $(1977,1979)$ the average (or average marginal) return to education in a given population is not much below the estimate that emerges from a simple cross-sectional regression of earnings on education. The "best available" evidence from the latest studies of identical twins suggests a small upward bias (on the order of $10 \%$ ) in the simple OLS estimates.

2. Estimates of the return to schooling based on comparisons of brothers or fraternal twins contain some positive ability bias, but less than the corresponding OLS estimates. Ability differences appear to exert relatively less influence on within-family schooling differences than on between-family differences.

3. IV estimates of the return to education based on family background are systematically higher than corresponding OLS estimates and probably contain a bigger upward ability bias than the OLS estimates.

4. Returns to education vary across the population with such observable factors as school quality and parental education.

5. IV estimates of the return to education based on interventions in the school system tend to be $20 \%$ or more above the corresponding OLS estimates. While there are several competing explanations for this finding, one plausible hypothesis is that the marginal returns to schooling for certain subgroups of the population - particularly those subgroups whose schooling decisions are most affected by structural innovations in the schooling system - are somewhat higher than the average marginal returns to education in the population as a whole.

While research over the past decade has made genuine progress on the question of the causal effect of education, it may be useful to conclude with a brief list of related topics that have not been as thoroughly addressed. One unresolved question is whether the private return to education - which is the focus of the microeconometric work surveyed here - is equal to, bigger, or smaller than the social return. This question lay at the center of the growth accounting controversy that stimulated much of the modern literature on the return to education, and has re-emerged in the past decade with the return of interest in sources of long-run economic growth. Indeed, much of the "new" growth theory focusses on the possible existence of significant externalities to education. ${ }^{84}$ The study of marketlevel externalities is obviously more difficult than the study of individual-level private returns to education: there are no "identical twins" at the market level. Nevertheless, some of the ideas that underlie the quasi-experimental studies of the private return to education

\footnotetext{
${ }^{84}$ See the chapter by Topel in this volume for a summary of the this literature with an emphasis on human capital issues.
} 
may be useful at the more aggregate level. For example, institutional changes in the school system may lead to shifts in the relative supply of better-educated workers in one area relative to another that can be used to construct market-level quasi-experimental contrasts.

A second (and related) question is whether the private return to education operates through a homogeneous shift in the productivity of better-educated workers, or through a more complex mechanism, such as differential access to different types of jobs. Some authors interpret the research on sheepskin effects described in Section 2 as distinguishing between these alternatives (see, e.g., Weiss, 1995). An innovative study of the market returns to a General Educational Development (GED) certificate by Tyler et al. (1998) suggests that credentials per se have a significant value in the US labor market, while other work (e.g., Cameron and Heckman, 1993) has questioned this hypothesis. ${ }^{85}$

A third question that has received renewed interest in the recent literature is how returns to education vary with observable characteristics, such as family background, school quality, ability, or location. One worthy goal of future research is to develop a better understanding of the extent to which the effects of permanent characteristics like family background on the returns to education "explain" their effects on educational attainment. A loftier goal is to understand the joint determination of schooling attainment and other endogenous outcomes like location or occupation in the context of a structural model of schooling and earnings determination.

A final issue that $I$ have ignored in this chapter is variation in the returns to education over time: either for the economy as a whole, or for fixed cohorts of individuals. Over the past 15 years the conventionally measured return to education has risen by $35-50 \%$ (see Autor et al., 1997, or the chapter by Katz and Autor in this volume). Relative to these shifts, the ability biases that are the focus of the literature reviewed here seem very modest in magnitude. Nevertheless, some authors have argued that changes over time in the overall return to education may be driven in part by changes in the magnitude of the ability bias components (e.g., Taber, 1998; Cawley et al., 1998). Some of the methods developed to study the extent of ability bias in a cross-sectional dataset can be extended to panel data, offering the possibility of modelling time-varying ability biases.

\section{Appendix A}

\section{A.l. OLS estimation of a random coefficients model}

Let $y$ denote a (scalar) outcome variable that is related to a $k$-dimensional covariate $X$

\footnotetext{
${ }^{85}$ Tyler et al.'s (1998) research design underscores the value of detailed institutional knowledge in helping to untangle causal mechanisms in the labor market. The GED certificate is awarded in lieu of high school graduation for successful completion of a test. In some states, however, the required test score to earn a GED is lower, allowing one to test whether the certificate itself is rewarded in the labor market, or only the underlying "knowledge". Tyler et al.'s results suggest that the certificate itself is important, since people with the same scores who would earn the degree in one state but not another appear to earn more when they have the degree.
} 
through a linear regression model with random intercept $\alpha$ and random slope coefficients $\beta$ :

$y=\alpha+X^{\prime} \beta+u=\bar{\alpha}+X^{\prime} \bar{\beta}+(\alpha-\bar{\alpha})+X^{\prime}(\beta-\bar{\beta})+u$

where $\bar{\alpha}$ and $\bar{\beta}$ denote the means of $\alpha$ and $\beta$, respectively, and $\mathrm{E}\left[X^{\prime} u\right]=0$. Denote the linear projections of $\alpha$ and $\beta$ on $X$ by

$\alpha-\bar{\alpha}=\lambda^{\prime}(X-\bar{X})+v_{1}$,

$\beta-\bar{\beta}=\psi(X-\bar{X})+v_{2}$,

where $\mathrm{E}\left[X^{\prime} v_{1}\right]=\mathrm{E}\left[X^{\prime} v_{2}\right]=0$ (by definition of $\lambda$ and $\psi$ ). Using these definitions,

$\mathrm{E}\left[(\beta-\bar{\beta})\left(X-X^{\prime}\right)\right]=\psi \mathrm{E}\left[(X-\bar{X})(X-\bar{X})^{\prime}\right]=\psi \operatorname{var}[X]$,

and therefore

$$
\begin{aligned}
\operatorname{cov}\left[X, X^{\prime}(\beta-\bar{\beta})\right] & =\mathrm{E}\left[(X-\bar{X})(\beta-\bar{\beta})^{\prime} X\right]=\mathrm{E}\left[(X-\bar{X})(\beta-\bar{\beta})^{\prime}(\bar{X}+(X-\bar{X}))\right] \\
& =\operatorname{var}[X] \psi^{\prime} \bar{X}+D
\end{aligned}
$$

where

$D=\mathrm{E}\left[(X-\bar{X})(X-\bar{X})^{\prime}(\beta-\bar{\beta})\right]$.

The probability limit of the OLS estimator of $\bar{\beta}$ for Eq. (A.1) is therefore

$$
\begin{aligned}
\operatorname{var}[X]^{-1} \operatorname{cov}[X, y] & =\operatorname{var}[X]^{-1}\left\{\operatorname{var}[X] \beta+\operatorname{var}[X] \lambda+\operatorname{var}[X] \psi^{\prime} \bar{X}+D\right\} \\
& =\bar{\beta}+\lambda+\psi^{\prime} \bar{X}+\operatorname{var}[X]^{-1} D
\end{aligned}
$$

Notice that if $X$ and $\beta$ are jointly symmetrically distributed then $D=0$. In this case the probability limit of the OLS regression coefficient is just

$\operatorname{plim}\left(\beta_{\mathrm{ols}}\right)=\bar{\beta}+\lambda+\psi^{\prime} \bar{X}$.

\section{A.2. Estimation of a random coefficients model}

Consider the estimation of Eq. (A.1) when a set of instruments $Z$ is available with the property that

$\mathrm{E}[(\alpha-\bar{\alpha}) \mid Z]=0$

$\mathrm{E}[(\beta-\bar{\beta}) \mid Z]=0$.

Assuming that $Z$ includes a vector of constants, denote the reduced form projection of $X$ on $Z$ by

$X=I I Z+v$. 
Finally, assume that

$\mathrm{E}[u \mid X, Z]=0, \quad \mathrm{E}[v \mid Z]=0$,

$\mathrm{E}[\alpha-\bar{\alpha} \mid X, Z]=\lambda_{x}^{\prime} X+\lambda_{z}^{\prime} Z$

$\mathrm{E}[\beta-\bar{\beta} \mid X, Z]=\psi_{x} X+\psi_{z} Z$

Assumption (A.5a) strengthens the orthogonality conditions defining the error components $u$ and $v$ into assumptions on conditional expectations. Assumptions (A.5b) and (A.5c) specify that the conditional expectations of $\alpha$ and $\beta$ are linear in $X$ and $Z$. Under these assumptions,

$0=\mathrm{E}[\alpha-\bar{\alpha} \mid Z]=\mathrm{E}\left[\lambda_{x}^{\prime}(\Pi Z+v)+\lambda_{z}^{\prime} Z \mid Z\right]=\left(\lambda_{x}^{\prime} \Pi+\lambda_{z}^{\prime}\right) Z$,

implying that $\lambda_{z}^{\prime}=-\lambda_{x}^{\prime} \Pi$. Similarly

$0=\mathrm{E}[\beta-\bar{\beta} \mid Z]=\mathrm{E}\left[\psi_{x}(I Z+\nu)+\psi_{z} Z \mid Z\right]=\left(\psi_{x} \Pi+\psi_{z}\right) Z$,

implying that $\psi_{z}=-\psi_{x} \Pi$. Substituting (A.5b) and (A.5c) into (A.1) and taking expections conditional on $(X, Z)$ yields

$$
\begin{aligned}
\mathrm{E}[y \mid X, Z] & =\bar{\alpha}+X^{\prime} \bar{\beta}+\lambda_{x}^{\prime} X+\lambda_{z}^{\prime} Z+X^{\prime}\left(\psi_{x} X+\psi_{z} Z\right) \\
& =\bar{\alpha}+X^{\prime} \bar{\beta}+\lambda_{x}(X-\Pi Z)+X^{\prime} \psi_{x}(X-\Pi Z) \\
& =\bar{\alpha}+X^{\prime} \bar{\beta}+\lambda_{x} \nu+X^{\prime} \psi_{x} \nu .
\end{aligned}
$$

Using standard arguments, (A.6) implies that consistent estimates of $\bar{\beta}$ can be obtained from a "control function" estimator that includes $X, \check{v}$ (the residual from a regression of $X$ on $Z$ ) and interactions of $X$ and $\check{v}$ (see also Garen, 1984). Notice that if $\beta$ is constant then the control function is simply $\tilde{v}$, yielding the conventional IV estimator. (In this case the preceding assumptions can be weakened by replacing the expectations operator in Eqs. (A.3) and (A.5) by the linear projection operator.)

\section{A.3. Measurement error in a bivariate regression model}

Consider a bivariate regression model

$y=X_{1} b_{1}+X_{2} b_{2}+u$

where $X_{1}$ and $X_{2}$ are measured with error. Denote the observed value of $X_{i}$ by $X_{i}^{o}(i=1,2)$, and assume that

$X_{1}{ }^{0}=X_{1}+\varepsilon_{1}, \quad X_{2}{ }^{0}=X_{2}+\varepsilon_{2}$,

where $\mathrm{E}\left[X_{i} \varepsilon_{j}\right]=\mathrm{E}\left[\varepsilon_{1} \varepsilon_{2}\right]=0$. Let $R_{1}$ and $R_{2}$ denote the reliability ratios of $X_{1}$ and $X_{2}$, respectively, where 
$R_{i} \equiv \operatorname{cov}\left[X_{i}^{\circ}, X_{i}\right] / \operatorname{var}\left[X_{i}^{\circ}\right]$.

Finally, consider the auxiliary regressions

$X_{1}=X_{1}{ }^{o} a_{11}+X_{2}{ }^{o} a_{12}+v_{1}$,

$X_{2}=X_{1}{ }^{\circ} a_{21}+X_{2}{ }^{\circ} a_{22}+v_{2}$,

where $v_{i}$ is orthogonal to $X_{1}^{(0}$ and $X_{2}^{\prime \prime}$ for $i=1,2$. The coefficients of these regressions can be expressed in terms of the variances of the observed $X^{\prime}$ 's, the reliability ratios, and $\rho$, the correlation of the observed covariates, $X_{1}^{0}$ and $X_{2}^{0}$. If $y$ is regressed on the observed $X^{\prime}$ s:

$y=X_{1}{ }^{\circ} c_{1}+X_{2}{ }^{\circ} c_{2}+e$,

the regression coefficients will equal

$c_{1}=b_{1} a_{11}+b_{2} a_{21}, \quad c_{2}=b_{1} a_{12}+b_{2} a_{22}$.

It is easy to show that

$c_{1}=b_{1} \frac{R_{1}-\rho^{2}}{1-\rho^{2}}+b_{2} \frac{1-R_{2}}{1-\rho^{2}} \times \frac{\operatorname{cov}\left[X_{1}{ }^{\circ}, X_{2}{ }^{\circ}\right]}{\operatorname{var}\left[X_{1}{ }^{\circ}\right]}$,
$c_{2}=b_{2} \frac{R_{2}-\rho^{2}}{1-\rho^{2}}+b_{1} \frac{1-R_{1}}{1-\rho^{2}} \times \frac{\operatorname{cov}\left[X_{1}{ }^{\circ}, X_{2}{ }^{\circ}\right]}{\operatorname{var}\left[X_{2}{ }^{\circ}\right]}$,

\section{References}

Akin, John S. and Irwin Garfinkel (1980), "The quality of education and cohort variation in black-white earnings differentials: comment", American Economic Review 70: 186-191.

Altonji, Joseph G. and Thomas A. Dunn (1995), "The effects of school and family characteristics on the return to education", Working paper no. 5072 (NBER, Cambridge, MA).

Altonji, Joseph G. and Thomas A. Dunn (1996a), "Using siblings to estimate the effect of school quality on wages", Review of Economics and Statistics 78: 665-671.

Altonji, Joseph G. and Thomas A. Dunn (1996b), "The effects of family characteristics on the return to schooling", Review of Economics and Statistics 78: 692-704

Angrist, Joshua D. and Guido W. Imbens (1995), "Two-stage least squares estimation of average causal effects in models with variable treatment intensity", Journal of the American Statistical Association 90: 431-442.

Angrist, Joshua D. and Alan B. Krueger (1991), "Does compulsory school attendance affect schooling and earnings", Quarterly Journal of Economics 106: 979-1014.

Angrist, Joshua D. and Alan B. Krueger (1992), "Estimating the payoff to schooling using the Vietnam-era draft lottery", Working paper no. 4067 (NBER, Cambridge, MA).

Angrist, Joshua D. and Alan B. Krueger (1995), "Split sample instrumental variables estimates of the return to schooling", Journal of Business and Economics Statistics 13: 225-235.

Angrist, Joshua D. and Victor Lavy (1997), "Using Maimonides' rule to estimate the effect of class size on scholastic achievement", Working paper no. 5888 (NBER, Cambridge, MA).

Angrist, Joshua D. and Whitney K. Newey (1991), "Over-identification tests in earnings functions with fixed effects", Journal of Business and Economic Statistics 9: 317-323. 
Angrist, Joshua D., Guido W. Imbens and Donald B. Rubin (1996), "Identification of causal effects using instrumental variables", Journal of the American Statistical Association 91: 444-472.

Ashenfelter, Orley and Colm Harmon (1998), "Editors introduction", Labour Economics (special issue on education), in press.

Ashenfelter, Orley and Alan B. Krueger (1994), "Estimates of the economic return to schooling for a new sample of twins", American Economic Review 84: 1157-1173.

Ashenfelter, Orley and Cecilia E. Rouse (1998), "Income, schooling and ability: evidence from a new sample of identical twins", Quarterly Journal of Economics 113: 253-284.

Ashenfelter, Orley and David Zimmerman (1997), "Estimates of the return to schooling from sibling data: fathers, sons and brothers", Review of Economics and Statistics 79: 1-9.

Autor, David H., Lawrence F. Katz and Alan B. Krueger (1997), "Computing inequality: have computers changed the labor market?" Working paper no. 5956 (NBER, Cambridge, MA).

Becker, Gary S. (1964), Human capital: a theoretical and empirical analysis, with special reference to education (Columbia University Press, New York).

Becker, Gary S. (1967), Human capital and the personal distribution of income (University of Michigan Press, Ann Arbor, MI).

Behrman, Jere R., Z. Hrubec, Paul Taubman and Terence J. Wales (1980), Socioeconomic success: a study of the effects of genetic endowments, family environment and schooling (North Holland, Amsterdam).

Behrman, Jere R., Robert Pollack and Paul Taubman (1982), "Parental preferences and the provision of progeny", Journal of Political Economy 90: 52-73.

Behrman, Jere R., Mark R. Rosenzweig and Paul Taubman (1994), "Endowments and the allocation of schooling in the family and the marriage market: the twins experiment", Jounal of Political Economy 102: 1131-1174.

Belman, Dale and John Heywood (1991), "Sheepskin effects in the return to education", Review of Economics and Statistics 73: 720-724.

Bound, John and David A. Jaeger (1996), "On the validity of season of birth as an instrument in wage equations: a comment on Angrist and Krueger's 'Does compulsory school attendance affect schooling and earnings?'”, Working paper no. 5835 (NBER, Cambridge, MA).

Bound, John, David A. Jaeger and Regina M. Baker (1995), "Problems with instrumental variables estimation when the correlation between the instruments and the endogenous explanatory variables is weak" "Journal of the American Statistical Association 90:443-450.

Butcher, Kristin F. and Anne Case (1994), "The effect of sibling composition on women's education and earmings", Quarterly Journal of Economics 109: 531-563.

Cameron, Stephen V. and James J. Heckman (1993), "The non-equivalence of high school equivalents", Journal of Labor Economics 11: 1-47.

Card, David (1995a), "Earnings, schooling and ability revisited", in: Solomon Polachek, ed., Research in labor economics, Vol. 14 (JAI Press, Greenwich, CT) pp. $23-48$.

Card, David (1995b), "Using geographic variation in college proximity to estimate the return to schooling", in: Louis N. Christofides, E. Kenneth Grant and Robert Swidinsky, eds., Aspects of labour market behaviour: essays in honour of John Vanderkamp (University of Toronto Press, Toronto, Canada) pp. 201-222.

Card, David and Alan B. Krueger (1992a), "Does school quality matter: returns to education and the characteristics of public schools in the United States", Journal of Political Economy 100: 1-40.

Card, David and Alan B. Krueger (1992b), "School quality and black-white relative earnings: a direct assessment", Quarterly Journal of Economics 107: 151-200.

Card, David and Alan B. Krueger (1996), "Labor market effects of school quality: theory and evidence", in: Gary Burtless, ed., Does money matter? The effect of school resources on student achievement and adult success (Brookings Institution, Washington, DC).

Cawley, John, James J. Heckman and Edward Vytlacil (1998), "Cognitive ability and the rising retum to education", Working paper no. 6388 (NBER, Cambridge, MA).

Chamberlain, Gary (1977), "Omitted variable bias in panel data: estimating the returns to schooling", Annals de l'Insee 30-31: 49-82. 
Chamberlain, Gary (1982), "Multivariate regression models for panel data", Journal of Econometrics 18: 5-46.

Chamberlain, Gary and Zvi Griliches (1975), "Unobservables with a variance components structure: ability, schooling and the economic success of brothers", International Economic Review 16: 422-449.

Chamberlain, Gary and Zvi Griliches (1977), "More on brothers", in: Paul Taubman, ed., Kinometrics (North Holland, Amsterdam).

Chiswick, Barry (1974), Income inequality: regional analysis within a human capital framework (Columbia University Press, New York).

Cohn, Elchanan and John T. Addison (1997), "The economic retums to lifelong learning", Working paper B-9704 (Division of Research, University of South Carolina College of Business Administration).

Conneely, Karen and Roope Uusitalo (1997), "Estimating heterogeneous treatment effects in the Becker schooling model", Unpublished discussion paper (Industrial Relations Section, Princeton University).

Dahl, Gordon B. (1997), "Mobility and the returns to education: testing a Roy model with multiple markets", Unpublished discussion paper (Industrial Relations Section, Princeton University).

Denison, Edward F. (1964), "Measuring the contribution of education", in: The residual factor and economic growth (OECD, Paris).

Freeman, Richard B. (1986), "Demand for education", in Orley Ashenfelter and Richard Layard, eds., Handbook of labor economics (North Holland, Amsterdam).

Garen, John (1984), "The returns to schooling: a selectivity bias approach with a continuous choice variable", Econometrica 52: 1199-1218.

Goodman, Jerry (1979), "The economic returns of education: an assessment of alternative models", Social Science Quarterly 60: 269-283.

Griliches, Zvi (1970), "Notes on the role of education in production functions and growth accounting", in: W. Lee Hansen, ed., Studies in income and wealth, Vol. 35 (Columbia University Press, New York).

Griliches, Zvi (1977), "Estimating the returns to schooling: some econometric problems", Econometrica 45: 122.

Griliches, Zvi (1979), "Sibling models and data in economics: beginnings of a survey", Journal of Political Economy 87: S37-S65.

Harmon, Colm and Ian Walker (1995), "Estimates of the economic return to schooling for the United Kingdom", American Economic Review 85: 1278-1286.

Hause, John C. (1972), "Eamings profile: ability and schooling", Journal of Political Economy 80: S108-\$138.

Hauser, Robert M. (1973), "Socioeconomic background and differential returns to education", in: Lewis C. Solomon and Paul J. Taubman, eds., Does college matter? Some evidence on the impacts of higher education (Academic Press, New York).

Hausman, Jerry A. and William E. Taylor (1981), "Panel data and unobservable individual effects", Econometrica 49: 1377-1398.

Heckman, James J. and Solomon Polachek (1974), "Empirical evidence on the functional form of the earningsschooling relationship", Journal of the American Statistical Association 69: 350-354.

Heckman, James J. and Edward Vytlacil (1998), "Instrumental variables methods for the correlated random coefficient model: estimating the rate of return to schooling when the return is correlated with schooling", Unpublished discussion paper (University of Chicago).

Heckman, James J., Anne Layne-Farrar and Petra Todd (1996), "Human capital pricing equations with an application to estimating the effect of school quality on earnings", Review of Economics and Statistics 78 : $562-610$.

Hungerford, Thomas and Gary Solon (1987), "Sheepskin effects in the return to education", Review of Econom ics and Statistics 69: 175-177.

Ichino, Andrea and Rudolf Winter-Ebmer (1998), "The long-run educational cost of World War II", Unpublished discussion paper (European University Institute).

Isacsson, Gunnar (1997), "Estimates of the return to schooling in Sweden from a large sample of twins", Unpublished discussion paper (Center for Research on Transportation and Society, Borlange, Sweden).

Jakubson, George (1988), "The sensitivity of labor supply parameter estimates to unobserved individual effects: 
fixed and random effects estimates in a nonlinear model using panel data", Journal of Labor Economics 6: 302-329.

Kane, Thomas J. and Cecilia E. Rouse (1993), "Labor market returns to two- and four-year colleges: is a credit a credit and do degrees matter?" Working paper no. 4268 (NBER, Cambridge, MA).

Kane, Thomas J., Cecilia E. Rouse and Douglas Staiger (1997), "Estimating returns to education when schooling is misreported", Unpublished discussion paper (Industrial Relations Section, Princeton University).

Kessler, Daniel (1991), "Birth order, family size and achievement: family structure and wage determination", Journal of Labor Economics 9: 413-426.

Kominski, Robert and Paul M. Siegel (1992), "Measuring educational attainment in the current population survey" (United States Department of Commerce Bureau of the Census, Population Division, Washington, DC).

Lang, Kevin (1993), "Ability bias, discount rate bias and the return to education", Unpublished discussion paper (Department of Economics, Boston University).

Link, Charles, Edward Ratledge and Kenneth Lewis (1980), "The quality of education and cohort variation in black-white earnings differentials: reply", American Economic Review 70: 196-203.

Maluccio, John (1997), "Endogeneity of schooling in the wage function", Unpublished manuscript (Department of Economics, Yale University).

Miller, Herman P. (1955), Income of the American people (United States Government Printing Office, Washington, DC).

Miller, Herman P. (1966), Income distribution in the United States (United States Government Printing Office, Washington, DC).

Miller, Paul, Charles Mulvey and Nick Martin (1995), "What do twins studies reveal about the economic returns to education? A comparison of Australian and U.S. findings", American Economic Review 85: 586-599.

Mincer, Jacob (1974), Schooling, experience and earnings (Columbia University Press, New York).

Murphy, Kevin M. and Finis Welch (1990), "Empirical age-earnings profiles", Journal of Labor Economics 8: 202-229.

Olneck, Michael R. (1979), "The effects of education", in: Christopher Jencks et al., eds., Who gets ahead? (Basic Books, New York)

Park, Jin Heum (1994), "Returns to schooling: a peculiar deviation from linearity", Working paper no. 335 (Industrial Relations Section, Princeton University).

Park, Jin Heum (1996), "Measuring education over time”, Economics Letters 60: 425-428.

Psacharopoulos, George (1985), "Returns to education: a further international update and implications", Journal of Human Resources 20: 583-604.

Psacharopoulos, George (1994), "Returns to investment in education: a global update", World Development 22: 1325-1343.

Rouse, Cecilia E. (1997), "Further estimates of the economic return to schooling from a new sample of twins", Unpublished discussion paper (Industrial Relations Section, Princeton University).

Siebert, W. Stanley (1985), "Developments in the economics of human capital", in: Labour economics (Longman, London).

Siegel, Paul M. and Robert Hodge (1968), "A causal approach to the study of measurement error", in: Hubert Blalock and Ann Blalock, eds., Methodology in social research (McGraw Hill, New York).

Smith, James P. and Finis Welch (1986), Closing the gap: forty years of economic progress for blacks (RAND, Santa Monica, CA).

Smith, James P. and Finis Welch (1989), "Black economic progress after Myrdal", Joumal of Economic Litera" ture 27: 519-564.

Staiger, Douglas and James H. Stock (1997), "Instrumental variables regression with weak instruments", Econometrica 65: 557-586.

Taber, Christopher (1998), "The college premium in the eighties: return to college or return to ability", Unpublished discussion paper (Department of Economics, Northwestern University).

Tyler, John H., Richard J. Murnane and John B. Willett (1998), "Estimating the impact of the GED on the 
earnings of young dropouts using a series of natural experiments", Working paper no. 6391 (NBER, Cambridge, MA).

Weiss, Andrew (1995), "Human capital vs. signalling explanations of wages", Journal of Economic Perspectives 9: $133-154$.

Welch, Finis (1973), "Black-white differences in returns to schooling", American Economic Review 63: 893-. 907.

Willis, Robert J. (1986), "Wage determinants: a survey and reinterpretation of human capital earnings functions", in: Orley Ashenfelter and Richard Layard, eds., Handbook of labor economics (North Holland, Amsterdam).

Willis, Robert J. and Sherwin Rosen (1979), "Education and self-selection", Journal of Political Economy 79 : S7-S36.

Wooldridge, Jeffrey M. (1997), "On two-stage least squares estimation of the average treatment effect in at random coefficient model", Economics Letters 56: 129-133.

Zheng, John (1996), "Specification testing and nomparametric estimation of the human capital model", Unpublished discussion paper (Department of Economics, University of Texas at Austin). 